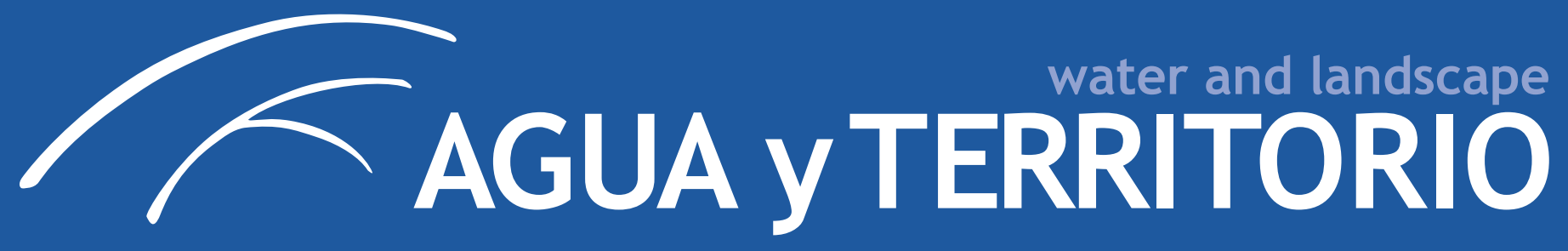

\title{
La explotación empresarial de las aguas mineromedicinales: la industria del agua embotellada en España (1875-2013)
}

\author{
The business use of the medicinal-mineral waters: \\ the bottled water industry in Spain (1875-2013) \\ Margarita Vilar-Rodríguez \\ ORCID: 0000-000I-9082-2734 \\ Elvira Lindoso-Tato \\ ORCID: 0000-0003-1004-5360
}

Universidade da Coruña. A Coruña, España. mvilar@udc.es; elviralt@udc.es

\begin{abstract}
Resumen - Desde un punto de vista histórico, la industria del agua embotellada ha pasado de ser un apéndice del negocio balneario a convertirse en una de las actividades más importantes de la industria alimenticia en Europa. Dentro de este sector, España ha registrado una de las expansiones más espectaculares en las últimas décadas, lo que le ha permitido escalar posiciones en el ranking europeo, tanto en términos de producción como en consumo per cápita. Este trabajo persigue dos objetivos básicos. Primero, conocer las diferentes etapas de la historia empresarial del agua envasada y la configuración de los grandes grupos empresariales que dominan el mercado español actual. Segundo, se aporta nueva información estadística sobre la producción y el consumo de agua embotellada desde una perspectiva de largo plazo y se reconstruyen las historias empresariales de las principales marcas de agua envasada líderes en el mercado.

Abstract - From a historical perspective, the bottled water industry went from an appendage of the spa business to one of the most important activities in the European food industry. Within this industrial sector, Spain registered a spectacular expansion in the last decades, growing in ranking both in the production and consumption per capita of bottled water in Europe. This article pursues two basic objectives. First, it seeks to identify the different stages of the bottled water business history and the make up of the great entrepreneurial groups that dominate the current Spanish market. Second, it provides new statistical data on production and consumption of bottled water from a long run perspective and it reconstructs the business history of the major bottled waters trademarks that lead the market.
\end{abstract}

Palabras clave: historia empresarial; aguas embotelladas; España; siglo XIX; siglo XX Keywords: business history; bottled waters; Spain; $19^{\text {th }}$ and $20^{\text {th }}$ centuries

Información Artículo: Recibido: 24 mayo 2014

Revisado: 15 julio 2014

Aceptado: 23 septiembre 2014

Código JEL: L79, N63, N64

( ) Universidad de Jaén / Seminario Permanente Agua, Territorio y Medio Ambiente (CSIC) 
La explotación empresarial de las aguas mineromedicinales: la industria del agua embotellada en España (1875-2013)

INTRODUCCIÓN

La producción de aguas embotelladas cuenta con una gran tradición histórica en España'. Sus primeros pasos se ligaron al desarrollo de los balnearios que se establecieron de forma intensa desde principios del $0_{\text {chocientos }}^{2}$. Algunos de estos establecimientos complementaron su negocio termal con el envasado de las aguas para que el usuario de los baños prolongase el tratamiento en sus casas. Más adelante, el preciado líquido empezó a embotellarse también como agua de mesa, lo que le permitió ampliar su mercado más allá de las fronteras medicinales impuestas por su naturaleza.

Desde una perspectiva histórica, España ha escalado posiciones en el subsector del agua envasada y se encuentra, hoy en día, en los primeros puestos de países consumidores de agua embotellada en el ámbito europeo -el tercero, tras Italia y Alemania, con un consumo por habitante de 136,5 litros durante el año 2012- y se convirtió en el séptimo país del mundo por consumo per cápita de agua envasada con 124 litros en el año 20103. Los principales informes sobre el sector señalan también que el agua envasada española es la más barata de Europa ${ }^{4}$. En los últimos treinta años, la producción de agua envasada española ha llegado a registrar en ocasiones tasas de crecimiento de dos dígitos, superando el ritmo de sus principales rivales europeos ${ }^{5}$. No obstante, su representatividad en el conjunto de la industria española resulta escasa. Así, la producción de aguas embotelladas y bebidas aromatizadas registró una cifra de negocios de 4.926 millones de euros en el año 2012 (el 0,86\% del total de la industria española, un 0,2\% en términos de número de empresas y el $0,64 \%$ en términos de empleo industrial). Pese a que no goza de inmunidad ante la gran recesión actual, el sector del agua ha mejorado sus resultados entre el año 2008 y el 2012 frente al conjunto de la industria nacional: esta registró tasas negativas de crecimiento mientras que el sector del agua creció un $58 \%$ entre 2008 y $2012^{6}$.

Las aguas embotelladas apenas han recibido atención por parte de los historiadores económicos. En España nos encontramos con algunas monografías centradas en las aguas de balnearios

1 Existen tres categorías de aguas envasadas: aguas minerales naturales, de origen subterráneo, protegidas contra los riesgos de contaminación, bacteriológicamente sanas y con una composición constante en minerales y otros componentes, lo que les confiere propiedades favorables para la salud; aguas de manantial que, a diferencia de las primeras, no han demostrado acción específica en el organismo humano; aguas preparadas, sometidas a los tratamientos fisicoquímicos necesarios para que cumplan los mismos requisitos sanitarios que se exige a las aguas potables de consumo público. Las primeras aguas embotelladas fueron las de la primera categoría, aunque desde mediados del siglo XX se han sumado al sector las del segundo y tercer grupo (véase http://www.aneabe.com/agua_envasada/tipos, consulta realizada el 30 de mayo de 2014).

2 Alonso, Lindoso y Vilar, 2011, 19-23.

3 En 2010, México, Italia, Emiratos Árabes Unidos, el tándem BélgicaLuxemburgo, Alemania y Francia se encontraban por encima, véase Lindoso y Vilar, 2014.

4 Revista Alimarket, 140, mayo de 2001, 249-269; 184, mayo de 2005, 235 256; 206, mayo de 2007, 221-243.

5 Por ejemplo, un 12,7\% en el año 1995, Revista Alimarket, 129, mayo de 2000, 199-217.

6 Las estadísticas oficiales no separan la producción de aguas embotelladas de las bebidas aromatizadas o azucaradas, véase Encuesta Industrial de Empresas, INE (consulta realizada el 5 de junio de 2014). históricos, pero estos trabajos adolecen del necesario análisis a largo plazo de la industria del agua envasada ${ }^{7}$. Esta carencia también resulta habitual en los estudios realizados en el ámbito internacional, donde escasean los trabajos enfocados en el progreso del sector desde una perspectiva global e histórica8.

Precisamente, el trabajo que el lector tiene en sus manos pretende profundizar en la evolución de la industria del agua embotellada en España desde dos puntos de vista. En primer lugar, haciendo hincapié en sus transformaciones empresariales desde una perspectiva histórica y, en segundo lugar, tratando de descubrir cómo el modelo de aguas español se inserta en la pauta europea analizada en Lindoso y Vilar (2014). Recordemos que, según este trabajo, Francia, Alemania e Italia han liderado históricamente este sector industrial en el viejo continente, tanto en la producción y el consumo como en la exportación y el marketing del producto. Hasta finales del siglo XIX, la industria del envasado constituyó en estos países líderes una actividad artesanal ligada al negocio balneario y al uso terapéutico de las aguas termales. Desde finales del Ochocientos, los talleres de envasado comenzaron a independizarse de los establecimientos balnearios y diversas empresas de tamaño creciente se encargaron de su explotación y distribución, llegando incluso a exportar sus aguas y, en definitiva, desligando su consumo de la cura termal in situ. Desde la década de 1960, el tamaño empresarial de lo que en su día fueron pequeños talleres familiares de embotellado escasamente mecanizados se incrementó mediante procesos de concentración empresarial y el empleo de nuevas tecnologías. Así, se inicia el surgimiento de las grandes multinacionales del sector en Europa. El fenómeno se intensificó en el último cuarto del siglo XX con numerosas fusiones $y$ adquisiciones de manantiales dentro y fuera de las fronteras nacionales, mientras el agua se transformaba en un bien de consumo básico presente en las estanterías de las tiendas de alimentación y en las grandes superficies comerciales.

Partiendo de este contexto, el trabajo se divide en dos grandes epígrafes. El primero abarca el estudio del sector del agua embotellada en España hasta finales de la década de 1950, un periodo caracterizado en el ámbito de la producción por el atraso tecnológico, la vinculación de la actividad embotelladora con el negocio balneario -en la mayoría de los casos- y un consumo ligado a las propiedades curativas de las aguas medicinales. El segundo apartado se inicia con el Plan de Estabilización y se prolonga hasta la actualidad. Durante estos años la industria de las aguas muestra una progresiva independencia respecto a la actividad balnearia, viéndose acompañada de la introducción de tec-

7 Véanse Benavente, Castillo y Cruz, 1999, y Benavente y Castillo, 1999, sobre las Aguas de Lanjarón, la tesis doctoral de Nobajas, 2012, para las aguas catalanas y los estudios sobre Vichy Catalán de Piernas, Pous y Planell, 1997, y Piernas, 2009. Por otra parte, las publicaciones de Alonso, Lindoso y Vilar, 2011; Larrinaga, 2011; Alonso, Vilar y Lindoso, 2012, y Larrinaga y Vallejo, 2013, estudian el sector termal en su conjunto y su inserción en la industria turística.

8 A destacar las obras de Green y Green, 1986; Delattre, 1999; Lamoreaux y Tanner (ed.), 2001; Gleick, 2010, y Marty, 2005, 2006, 2008 y 2011 que abarcan tanto catálogos más o menos exhaustivos de aguas como estudios sobre la producción nacional de países, sobre todo del caso francés. Lindoso y Vilar, 2014, ofrecen un primer análisis global del sector en Europa desde la perspectiva de la historia económica y un pequeño avance del caso español.

9 Más detalles sobre el proceso de desarrollo de la industria del agua envasada europea, en Lindoso y Vilar, 2014. 
nologías de nuevo cuño que revolucionaron el sector. En paralelo, la creciente demanda de agua embotellada, la puesta en marcha de modernas campañas de marketing ligadas a un nuevo concepto de bienestar y vida saludable y la introducción de nuevas estrategias empresariales transformaron una industria que de manera progresiva convergió hacia las pautas observadas en otros países europeos, aunque con sus características propias.

LOS PRIMEROS PASOS DE LA INDUSTRIA DEL AGUA EMBOTELLADA EN ESPAÑA: LA DEPENDENCIA DEL NEGOCIO BaLNEARIO, 1875-1959

Hasta el último cuarto del siglo XIX, el negocio del agua embotellada en España permaneció como una actividad artesanal dependiente de los balnearios y sus tratamientos terapéuticos. Por tanto, el devenir de la actividad embotelladora acompañó a los vaivenes del sector termal. En general, el desarrollo del balneario precedió al de los talleres de embotellado, aunque hubo algunas excepciones. La primera reglamentación de calado de los establecimientos termales llegó en 1816 con la declaración de utilidad pública y la imposición de un director médico ${ }^{10}$. En paralelo, se reconocieron de manera progresiva los derechos de los propietarios. Primero, la legislación de las Cortes de Cádiz cedió la propiedad a los poseedores del dominio útil, que solía recaer en los vecinos, decisión confirmada durante el reinado de Fernando VII. Pero la cesión mayoritaria de la propiedad de las aguas a los bienes propios de los municipios colindantes derivó en un abandono de los balnearios debido a la falta de recursos. Más adelante, la desamortización de Madoz de 1855 terminó de definir los derechos de propiedad e impulsó la transferencia masiva de los baños a particulares, lo que favoreció a medio plazo la explotación empresarial de las aguas (Apéndice).

Hacia 1886, se mantenían de forma residual instalaciones con características propias de la etapa del Antiguo Régimen: indefinición de la propiedad, falta de inversión y precariedad. Se trataba de seis establecimientos participados por los vecinos (antiguos comunales), once pertenecientes a municipios y diputaciones provinciales (antiguos bienes de propios) y uno al clero (en disputa con los vecinos). En conjunto, una décima parte del total componía los restos del naufragio de los bienes del Antiguo Régimen tras la oleada desamortizadora y privatizadora. Los restantes establecimientos se configuraban como propiedad consolidada (16 de ellos en manos de la aristocracia). Asimismo, es necesario destacar también el avance de las sociedades anónimas. Aunque el Apéndice no explicita con suficiente claridad el número de empresarios que las conformaban, puede deducirse que alcanzaban un porcentaje cercano al treinta por ciento, mientras que el resto se mantenía en la condición de empresarios individuales ${ }^{11}$. La

10 Los reales decretos de 29 de junio, 9 de julio y 16 de agosto de 1816; la real orden de 28 de noviembre de 1816 y, sobre todo, el Reglamento de 28 de mayo de 1817 dieron cobertura legal al sector. Véase Alonso, Lindoso y Vilar, 2011, 20.

11 La conjunción de la privatización con la mejora de las infraestructuras, los servicios de correo y la mayor estabilidad política del país tras la derrota militar del carlismo pusieron las bases del desarrollo del sector en la segunda mitad del siglo XIX, véase Alonso, Vilar y Lindoso, 2012. transformación del modelo balneario repercutía en la industria del agua embotellada, todavía vinculada al negocio termal.

En general, durante esta etapa encontramos tres posibles vías de explotación de los manantiales: la terapéutica, que abarcaba los tratamientos con agua mineromedicinal a una tarifa fija recibidos por los agüistas/bañistas que acudían durante la temporada oficial; la preparación de productos derivados del agua, tales como sales minerales y cosméticos, y el embotellado de las aguas en sus dos vertientes, aguas terapéuticas y aguas de mesa. La primera vía resultaba común a casi todos los establecimientos balnearios con reconocimiento oficial, e incluso a aquellos de carácter clandestino. Las últimas vías aparecían más restringidas, dependiendo de las características de las aguas, la demanda y/o los capitales disponibles.

A su vez, podemos diferenciar cuatro tipos de establecimientos que ofrecían aguas en bebida y que lideraron el mercado del agua embotellada en la segunda mitad del siglo XX (Tabla 1). El primer grupo, el más numeroso, integrado por balnearios destinados a las clases populares que iban a "tomar las aguas" en la temporada veraniega directamente de la fuente ya que no contaban con planta embotelladora. Se trataba, por lo general, de balnearios con instalaciones modestas en manos públicas (ayuntamientos, vecinos...) o pertenecientes a propietarios individuales con escasa capacidad de inversión que, en muchas ocasiones, ni siquiera ofrecían alojamiento. El segundo grupo se refiere a establecimientos que pudieron modernizarse gracias a su mayor capacidad de inversión y trataron de reproducir el modelo europeo de centros de sociabilidad que ofrecían instalaciones hoteleras de alto standing y combinaban la oferta de tratamientos termales en baños y bebida con actividades culturales y de ocio. En la mayoría de los casos estaban gestionados por empresas modernas, que asumían en ocasiones la forma jurídica de sociedades anónimas. Estos establecimientos comenzaron a invertir en plantas embotelladoras anexas a las instalaciones balnearias, predominantes todavía en los intereses empresariales a finales del siglo XIX. Este fue el caso, por ejemplo, de los balnearios de Mondariz o Cabreiroá, muy ligados a la edad de oro balnearia de la Belle Époque, que envasaban y comercializaban sus aguas antes de la I Guerra Mundial vinculadas a instalaciones balnearias de alto nivel. En particular, el balneario de Mondariz registraba unas ventas de un millón y medio de botellas en el año 1910, cifra cercana al de algunas fuentes francesas líderes en el mercado europeo ${ }^{12}$.

Otros balnearios, cuyas aguas envasadas alcanzaron gran éxito en las décadas siguientes, comenzaron a explotar sus plantas embotelladoras más tarde, en los años veinte y treinta. Este fue el caso, por ejemplo, de Solares, Solán de Cabras y Lanjarón que no contaron con la capacidad inversora de otros establecimientos. De los dos primeros disponemos de escasa información. Por lo que se refiere a Lanjarón, fue adquirido por la familia Carrillo a finales del siglo XIX. Los nuevos propietarios modernizaron las instalaciones balnearias y desarrollaron a mayor escala la comercialización del agua embotellada ${ }^{13}$. De este modo, desde comienzos del nuevo siglo las cajas de 25 botellas se vendían 0

\footnotetext{
12 Lindoso y Vilar, 2014.

13 Piñar, 2006.
} 
La explotación empresarial de las aguas mineromedicinales: la industria del agua embotellada en España (1875-2013)

Tabla 1. Marcas históricas de agua embotellada en España

\begin{tabular}{|c|c|}
\hline Marca & Propiedad $^{*}$ \\
\hline VICHY CATALAN (Girona) & 1881 Dr. Modest Furest \\
\hline \multirow{3}{*}{ Utilidad pública: 1833} & 1900 Sociedad Anónima Vichy Catalán \\
\hline & $\begin{array}{l}1990 \text { Grupo Vichy Catalán: S.A. Vichy Catalán y Malavella S.A, ubicadas en Caldes de Malavella; } \\
\text { Fontdor S.A., en San Hilario Sacalm; Agua Las Creus S.A. de Maçanet de Cabrenys y Font del } \\
\text { Regás, S.A. en Arbúcies (Girona) }\end{array}$ \\
\hline & 1994 adquisición de Aguas de Mondariz- Fuente del Val, S.A. \\
\hline CARABAÑA (LA FAVORITA) (Madrid) & 1864 Ruperto Jacinto Chavarri \\
\hline \multirow{4}{*}{ Utilidad pública: 1928} & 1911 Viuda e Hijos de Chavarri (Julia Batres) \\
\hline & 1928 Hijos de J. R. Chávarri \\
\hline & 1948 Chávarri, S. A. Aguas de Carabaña-La Favorita \\
\hline & 2007 Grupo Foxa \\
\hline LANJARÓN (Granada) & Posesión pública municipal y de la Diputación de Granada \\
\hline \multirow{10}{*}{ Utilidad pública:1833 } & $\begin{array}{l}1873 \text { Expropiado y adquirido por María del Carmen Hernández Espinosa de los Monteros } \\
\text { (Duquesa Viuda de Santoña) } \\
1894-1896 \text { fallecimiento de la duquesa. Balneario en manos de acreedores y venta pública por } \\
\text { parte del financiero y agente de bolsa madrileño Francisco López Bayo }\end{array}$ \\
\hline & 1897 Silverio Carrillo \\
\hline & 1922 José y Matilde Carrillo Nogueras (Comunidad de bienes) \\
\hline & 1935 Balneario y Aguas de Lanjarón (participada por los dos hermanos) \\
\hline & 1940 Hijas de la Caridad de San Vicente de Paul (a) \\
\hline & 1946 Manuel Gallardo Torrens \\
\hline & $\begin{array}{l}1970 \text { Banco de Granada (que quiebra, y es comprado todo el lote por el Banco Central que, a } \\
\text { su vez, lo vende a Aguas de Barcelona) }\end{array}$ \\
\hline & 1970s Aguas de Barcelona \\
\hline & 1990s Danone \\
\hline & 2006 Aguas Font Vella y Lanjarón, S.A. \\
\hline SOLARES (Cantabria) & 1886 Ramón Pérez del Molino \\
\hline \multirow{4}{*}{ Utilidad pública: 1882} & 1909 Sociedad (Madrid) \\
\hline & $\begin{array}{l}1977 \text { Solicita suspensión de pagos (tras escándalo por contaminación) y queda en manos de la } \\
\text { Diputación Regional (b) }\end{array}$ \\
\hline & 1987 Adquirida por la familia Añíbarro (vinculada al mundo del café) \\
\hline & 1994 Balneario de Solares S. L. (c) \\
\hline SOLÁN DE CABRAS (Cuenca) & 1886 Vicente Saiz \\
\hline \multirow{4}{*}{ Utilidad pública: 1790} & $\begin{array}{l}\text { c.1990 Balneario y Agua de Solán de Cabras S.L. (tres familias: Del Pozo, Sanz Gallego y García } \\
\text { Cabanes) }\end{array}$ \\
\hline & 1999 Damm (entra como accionista y en 2000 se hace con el control de la compañía) \\
\hline & 2001 Grupo Osborne (entra como accionista y se hace con el control en los años siguientes) \\
\hline & 2011 Grupo Mahou-San Miguel \\
\hline AGUAS DE MONDARIZ-FUENTE DEL VAL (Pontevedra) & 1896 Sociedad de Aguas de la Fuente del Val \\
\hline \multirow{3}{*}{ Utilidad pública: 1897} & 1924 Aguas de Mondariz Fuente del Val S.A. \\
\hline & $\begin{array}{l}1988 \text { Fusión entre Aguas de Mondariz Fuente del Val S.A. (marca Fuente del Val) y Aguas de } \\
\text { Mondariz, Hijos de Peinador S.A. (Marca Mondariz) }\end{array}$ \\
\hline & 1994 Venta de planta embotelladora al Grupo Vichy Catalán \\
\hline CABREIROÁ (Ourense) & 1909 F. Salgueiro y G. Barbón \\
\hline \multirow{2}{*}{ Utilidad pública: 1906} & 1973 Aguas de Cabreiroá S.A. \\
\hline & 2006 Hijos de Rivera S.A. \\
\hline
\end{tabular}

* Refleja los cambios de propietarios y/o denominación empresarial disponibles.

(a) finales de los años treinta, sor Matilde, debido a su precario estado de salud, decide donar su participación en el Balneario a su Congregación de las Hijas de la Caridad de San Vicente de Paul, y estas, a su vez, en 1940 le compran su parte a José Carrillo, haciéndose dueñas de las "Aguas y Baños minero medicinales de Lanjarón”. Concluye así la relación de la familia Carrillo con el Balneario (http://www.iaph.es/patrimonio-inmueble-andalucia/resumen.do?id=i21790, consulta realizada el 30 de mayo de 2014).

(b) El Gran Hotel Balneario de Solares se cerró al público en 1976. Paralelamente, la empresa embotelladora cayó en picado y el agua del manantial de Fuencaliente, se envasa actualmente bajo la marca Agua de Solares S.A., con el nombre de Manantial de Fuentecaliente S.A.

(c) Sigue en manos de la familia Añibarro. Su capital social pertenece en un $98 \%$ a la firma "Manantial de Fuencaliente", quedando el $2 \%$ restante en manos de los propios socios que integran la empresa matriz (http://www.cantabriaeconomica.com/index.php?envio=noticiactidnoticia=2010, consulta realizada el 30 de mayo de 2014).

Fuentes: Alonso, Lindoso y Vilar, 2011, y Alonso, Vilar y Lindoso, 2012. SABI (consulta realizada el 6 de junio de 2014), páginas web de las empresas y la bibliografía mencionada en este trabajo. 
Tabla 2. Primeras marcas de agua embotellada mineromedicinal registradas en España 1888-1910

\begin{tabular}{|c|c|c|c|c|}
\hline Denominación & $\begin{array}{l}\text { Fecha solicitud } \\
\text { marca- caducidad }\end{array}$ & Localidad & Propietario & Cesión \\
\hline Aguas de Mondariz VHP & $\begin{array}{l}12 \text { de enero de } 1888- \\
6 \text { de julio de } 1891\end{array}$ & Pontevedra & Viuda e Hijos de Peinador & No \\
\hline Vichy Catalán & 24 de diciembre de 1889 & Girona & Furest y Compañía & $\begin{array}{l}6 \text { de noviembre de } 1907 \\
\text { - Vichy Catalán, S. A } \\
\end{array}$ \\
\hline $\begin{array}{l}\text { Fuente Agria / } \\
\text { Aguas de Villaharta }\end{array}$ & \begin{tabular}{|l|}
30 de junio de $1894-$ \\
15 de diciembre de 1914
\end{tabular} & Córdoba & Cervelló Chinesta, Elías & No \\
\hline Aguas de Mondariz & \begin{tabular}{|l|}
27 de junio de $1902-$ \\
11 de abril de 1939 \\
\end{tabular} & Pontevedra & \begin{tabular}{|l|} 
Peinador Vela, Sabino Enrique / \\
Peinador Vela, Gumersindo Ramón
\end{tabular} & No \\
\hline El Vichy Catalán & 14 de octubre de 1902 & Girona & Vichy Catalán, S. A. & No \\
\hline Caldas de Malavella & 6 de marzo de 1903 & & Solé Font, Teresa & No \\
\hline Agua de Caldas de Malavella & 15 de abril de 1903 & & Solé Rulló, José & No \\
\hline $\begin{array}{l}\text { Aguas de Mondariz - } \\
\text { Fuente del Val }\end{array}$ & \begin{tabular}{|l|}
23 de junio de $1903-$ \\
18 de junio de 1909 \\
\end{tabular} & Pontevedra & Aguas de Mondariz-Fuente del Val & No \\
\hline $\begin{array}{l}\text { Aguas Minerales Naturales } \\
\text { de Caldas de Malavella }\end{array}$ & \begin{tabular}{|l|}
19 de enero de 1906- \\
29 de septiembre de 1911 \\
\end{tabular} & Girona & Rosell Sebastiá, Ramón & No \\
\hline El Vichy Catalán & 8 de enero de 1907 & & Vichy Catalán, S. A. & No \\
\hline $\begin{array}{l}\text { Aguas minero-medicinales } \\
\text { de Verín }\end{array}$ & \begin{tabular}{|l|}
8 de abril de 1907- \\
31 de octubre de 1917 \\
\end{tabular} & Ourense & Salgueiro García-Barbón, Feliciano & No \\
\hline Agua Carabaña & $\begin{array}{l}15 \text { de octubre de } 1907- \\
30 \text { de mayo de } 1969 \\
\text { (hubo una } 2^{\text {a }} \text { solicitud en } \\
10 \text { de junio de } 1908 \text { ) }\end{array}$ & Madrid & Chávarri Hernáiz, Ruperto Jacinto & $\begin{array}{l}21 \text { de octubre de } 1913 \text { - } \\
\text { Viuda e Hijos de R. J. Chávarri } \\
9 \text { de febrero de } 1928 \\
\text { Hijos de J. R. Chávarri } \\
\\
6 \text { de noviembre de } 1948 \\
\text { Chávarri, S. A. Aguas de Carabaña } \\
\text { La Favorita }\end{array}$ \\
\hline El Vichy Catalán & 12 de marzo de 1910 & Girona & Vichy Catalán, S. A. & No \\
\hline Agua de Borines & $\begin{array}{l}27 \text { de abril de } 1910- \\
25 \text { de junio de } 1919\end{array}$ & Asturias & Ballesteros Vicente, Lázaro & No \\
\hline
\end{tabular}

Fuente: Archivo Histórico de la Oficina Española de Patentes y Marcas (http://historico.oepm.es/archivohistoricow3c/index.asp\#formulario_marcas, consulta realizada el 5 de junio de 2014).

bien directamente o bien a través de concesionarios en la ciudad de Granada. Tras la muerte del patriarca José Carrillo en 1922, sus hijos José y Matilde, tomaron el testigo y crearon más tarde la sociedad Balneario y Aguas de Lanjarón en 1935. En los años veinte y treinta, al amparo del dinamismo empresarial de los prohombres del lugar, Lanjarón acabaría siendo el lugar de veraneo más importante de Granada, donde acudía lo más selecto de su pequeña burguesía.

Por último, podemos destacar marcas históricas como, por ejemplo, Vichy Catalán o La Favorita (Carabaña, Madrid) donde la actividad embotelladora resultó precoz. En el caso de Vichy Catalán, fundada por el doctor Modest Furest, se inauguró primero la planta de embotellado (1890) y después empezó a tomar cuerpo el proyecto de construcción de un balneario moderno, cuya primera sección se inauguró en 1898. El proyecto empresarial exigió grandes inversiones económicas y el doctor Furest buscó socios que apoyasen la iniciativa. Consiguió la aportación de capital de cuatro prohombres, cuya fortuna procedía de los negocios que tenían en Cuba. Bonaventura Blay y Milà, Josep Ferrer y Torralbas, Josep Serradell y Amich y Josep Vias Camps fundaron con
Modest Furest i Roca la Sociedad Anónima Vichy Catalán, el 16 de junio de 1900. Un año más tarde, se incorporaría el también indiano Antoni Serra y Ferret. El éxito del agua envasada hizo necesario un nuevo proyecto de planta embotelladora en 1905, con instalaciones más amplias y maquinaria más moderna ${ }^{14}$. Por su parte, en el manantial de Carabaña (Madrid) se explotaba "La Favorita", una marca de agua reconocida desde finales del siglo XIX en el ámbito internacional. La familia Chavarri, dueños del establecimiento, plantearon un proyecto de balneario moderno en 1892 que finalmente no se llevó a cabo. El negocio acabó por concentrarse en el embotellado de agua. Entre 1928-1936 la empresa llegó a contar con más de un centenar de empleados y mantenía capacidad para producir más de tres millones de botellas anuales, destinadas al consumo nacional e internacional ${ }^{15}$. Un caso parecido encontramos en Gran Canaria con las Aguas de Firgas, que surgieron de la fusión de Fuente La Ideal de "González 14 http://www.grupovichycatalan.es/historia2ES.php (consulta realizada el 4 de junio de 2014).

15 http://filirp-alternativasnaturales.blogspot.com.es/2011/06/agua-decarabana.html y http://geomadriles.blogspot.com.es/2013/12/las-aguas-minerales-de-madrid-aguas-de.html (consulta realizada el 4 de junio de 2014). 
La explotación empresarial de las aguas mineromedicinales:

la industria del agua embotellada en España (1875-2013)

y Arencibia" y Fuente Agria de "Ríos y Compañía" el 7 de agosto de 1930. Con una planta embotelladora de más de doce mil $\mathrm{m}^{2}$ en el Barranco de la Virgen, rápidamente se convirtió en el líder de aguas gasificadas de Canarias, teniendo como nombre inicial La Ideal I' ${ }^{16}$.

En general, el desarrollo de la actividad embotelladora de agua en los años de cambio de siglo se revela en el registro de marcas y patentes, mostrando quiénes eran los líderes del sector en esta etapa inicial (Tabla 2). En paralelo, conforme se afianzaba su carácter de empresa privada, los balnearios españoles de mayor prestigio buscaron su reconocimiento en Europa y el resto del mundo. Y lo hicieron a través de su presencia en las exposiciones internacionales que comenzaban a celebrarse en la segunda mitad del siglo XIX. Buscaban con ello la publicidad más directa brindada por la obtención de distinciones, que hacían figurar en sus anuncios en la prensa, pero también obtenían una rentabilidad de más largo plazo y de carácter exterior. Las primeras exposiciones - la Exposición Internacional de Londres de 1862, la de París (1867), la mundial de Viena (1873) y la de Artes, manufacturas y productos del suelo y minas de Filadelfia (1876) - contaron con la presencia de un reducido número de expositores españoles. Sin embargo, para la Exposición Universal de París (1878) el gobierno estimuló la participación de las empresas con mayores recursos ${ }^{17}$. Finalmente, las aguas españolas acudieron con un pequeño stand que obtuvo reconocimientos alentadores. Las aguas de Lanjarón, Fuencaliente, Hervideros de Fuensanta y las de Sant Hilari Sacalm, entre otras, resultaron premiadas ${ }^{18}$. Una feria posterior, la Exposición de tecnología balnearia de Frankfurt (1881), distinguió con diversos diplomas a los establecimientos termales más vanguardistas, bien porque eran de nuevo cuño o bien porque siendo tradicionales se habían adaptado a las nuevas exigencias de los consumidores, rubricando así la calidad de las aguas españolas ${ }^{19}$. Estas siguieron promocionándose hasta las vísperas de la I Guerra Mundial y recibieron diversos galardones. Así sucedió otra vez con las aguas de Sant Hilari Sacalm, Caldes de Malavella, Mondariz, Hervideros de Fuensanta, Borines, Solares, Aguas del Lérez, Carabaña, Fontenova, Villaza o Panticosa ${ }^{20}$. En paralelo, a comienzos del siglo XX, se creaba la primera patronal frente a los intereses de los médicos directores y de la intervención del Estado, la denominada Asociación de Propietarios de Balnearios y de Manantiales de aguas minero-medicinales de España (1906), todo un hito de la madurez del sector.

Tras la I Guerra Mundial, el despertar empresarial de las aguas embotelladas convivió con algunos factores que frenaron el negocio balneario. En primer lugar, las presiones de la medicina farmacológica contribuyeron en gran medida a que los balnea-

16 http://www.grancanariagourmet.com/blog/2012/06/agua-de-firgas-seincorpora-a-gran-canaria-gourmet/ (consulta realizada el 4 de junio de 2014).

17 Anales de la Sociedad Española de Hidrología Médica, tomo I, 1877-1878, 49 y ss.

18 Anuario oficial de las aguas minerales de España, tomo II, 1882, 492.

19 Véanse La Iberia, 29 de septiembre de 1881, 7668, 3; La llustración Española y Americana, 23 de octubre de 1881, año I, 51, 3, y Anuario oficial de las aguas minerales de España, tomo II, 1882, 493.

20 La Vanguardia (Barcelona), 8 de septiembre de 1883, 20; Anales de la Sociedad Española de Hidrología Médica, tomo XIII, 1898, 2, 224; Ibídem, tomo XIX, 1907, 6, 139-140, Ibídem, tomo XX, 1908, 1, 24. rios se abandonaran como centros de salud ${ }^{21}$. Por otro lado, los avances en la medicina hospitalaria y cirugía, la competencia del turismo de ola o la inestabilidad política de la II República afectaron de manera negativa a la demanda termal en España. Pero ¿cómo afectaron estos factores a los talleres de embotellado? Si bien es cierto que las estancias medias en los balnearios se redujeron, el retroceso sirvió de estímulo a algunos establecimientos para especializarse en la industria del embotellado de aguas. Un segmento de negocio que según las escasas cifras aportadas por la EME repuntó durante la década de 1930 (Tabla 3). Los datos de los establecimientos canarios y gerundenses resultaban bastante contundentes. Los manantiales de Las Palmas vendieron 2.102.000 de botellas de agua envasada en el año 1932. En vísperas de la guerra civil, superaban los cinco millones. Entre ellos, destacaban los manantiales de Teror, San Roque, La Ideal, Fuente Agria, Los Berrazales y Firgas. En Girona, sobresalía la empresa Vichy Catalán que, en 1935, había multiplicado por 2,5 los litros producidos en 1920. Sus botellas de agua con gas se exportaban a México, Argentina, Uruguay, Cuba, Filipinas y Brasil. Durante las décadas de 1920 y 1930, la compañía gerundense había invertido en mejorar la planta de embotellamiento, instalando diversa maquinaria moderna tales como lavadoras automáticas, máquinas para taponar las botellas o rotativas de veinte grifos para la sección de llenado. De esta manera, se multiplicó su cifra de nego$\mathrm{Cio}^{22}$. Por el contrario, las ventas de las aguas de Cestona, Alzola e Insalus (Guipúzcoa) decayeron durante la década de 1930, tanto en valor como en cantidad, y llegado el año 1946, no habían vuelto a recuperar los niveles de la década de 1920 (623.025 botellas valoradas en 639.235 pesetas en el año 1924) ${ }^{23}$.

Tabla 3. Ventas de botellas de agua envasada en España, 1888-1970

\begin{tabular}{|l|r|l|r|}
\hline \multicolumn{1}{|c|}{ Año } & \multicolumn{1}{c|}{ Núm. Bot. } & \multicolumn{1}{c|}{ Año } & \multicolumn{1}{c|}{ Núm. Bot. } \\
\hline Media 1888-1891 & 16.061 & Media 1940-1949 & 8.213 .768 \\
\hline 1907 & 1.500 .000 & Media 1950-1955 & 10.358 .693 \\
\hline 1910 & 4.506 .000 & 1960 & 12.000 .000 \\
\hline Media 1920-1929 & 1.454 .550 & 1970 & 43.000 .000 \\
\hline Media 1930-1939 & 5.684 .345 & & \\
\hline
\end{tabular}

Nota: la tabla se ha elaborado a partir de datos puntuales de algunos años y sólo de las botellas expedidas por algunos establecimientos que figuran en la Estadística Minera de España. La EME apenas aporta información regular sobre las botellas vendidas y/o producidas en España hasta 1955. De hecho, es necesario rellenar las lagunas estadísticas con las memorias y los informes médicos de los balnearios así como con los datos de la Oficina de Patentes y Marcas, en especial hasta la segunda década del siglo XX cuando las ausencias estadísticas resultan más notorias. Hay que tener en cuenta también que se suele desconocer la capacidad de los envases, lo que dificulta una correcta medición.

Fuentes: Pereira, 2009, 126-138; Alonso, Lindoso y Vilar, 2011, capítulo dedicado a las aguas de Verín; Piernas, 2009, 44-45; Archivo Histórico de la Diputación de Pontevedra (en adelante AHDP), Contribución de Utilidades, Aguas de Mondariz de Hijos de Peinador, 1941; Sousa. Orense. 1890; Memoria facultativa reglamentaria del Establecimiento hidromineral de Verín, Sousas y Caldeliñas, provincia de Orense. Temporada de 1891; Memoria Mondariz año 1879; Estadística Minera de España (EME), años 1900-1955; Piernas et al., 1997, 107-142.

21 Anales de la Sociedad Española de Hidrología Médica, tomo XXXVIII, 1930, 2, 58-59.

22 Piernas et al., 1997, 107-142. Piernas, 2009, 44-45.

23 Estadística Minera de España (EME), 1924-1946. 
A excepción de la empresa Vichy Catalán, el proceso de envasado resultaba primitivo todavía. En muchos establecimientos las aguas se embotellaban de forma manual con el fin de que los agüistas/bañistas prolongasen los efectos beneficiosos del tratamiento en sus casas. En algunos casos, el éxito de esta iniciativa impulsó el desarrollo de plantas de embotellado anexas a los balnearios, formando un todo indisoluble, que mantenían un carácter artesanal y exigían escaso desarrollo tecnológico y financiación. De este modo, la mayor parte de las aguas susceptibles de envasado ${ }^{24}$ se embotellaban directamente en la surgencia en botellas de cristal o tarros de cerámica/cristal, luego eran sellados, por lo general con corcho o cera, y embalados en cajas de madera forradas de paja para evitar roturas. El agua apenas recibía tratamiento alguno en este proceso. El personal contratado lavaba las botellas a mano y se llenaban directamente de la fuente. A continuación, se taponaban, se embalaban y distribuían directamente por el balneario o bien por sus agentes en farmacias y en pequeños establecimientos comerciales, reconociendo de esta forma su carácter terapéutico y contribuyendo a la extensión de su fama y empleo más allá de los círculos locales. Los puntos de venta se localizaban en mercados próximos y, a veces, llegaban a introducirse en el interior peninsular y en el extranjero -en especial, el mercado americano y, en ocasiones, el europeo- sobre todo a finales del Ochocientos. Este es un fenómeno en el que merece la pena detenerse dado que esta vocación exportadora no se mantuvo en el mismo grado durante el resto del siglo XX.

De hecho, el incremento de las exportaciones de las botellas de agua en algunas instalaciones se veía favorecido de manera habitual por los lazos que los dueños y/o fundadores habían establecido con el continente americano o europeo. Muchos de ellos se clasificaban como indianos, emigrantes que volvían enriquecidos a su país de origen y que invertían parte de la fortuna obtenida haciendo las Américas en actividades filantrópicas y productivas, tales como la inversión en establecimientos termales. Empresarios como Casimiro Gómez en el balneario del Lérez (Pontevedra), José Manuel García Barbón en Cabreiroá (Ourense) o la mayoría de los socios de la primigenia compañía anónima Vichy Catalán ${ }^{25}$ (Girona) aprovecharon sus relaciones con América para realizar una activa campaña de promoción de sus productos en el continente. De esta manera, las Aguas del Lérez mantenían una casa central en Buenos Aires, dado que su principal mercado se localizaba en Suramérica, mayoritariamente en Argentina. Por otro lado, W. J. Balter, J. Cdilliarns y F. W. Wade, beneficiarios de la comercialización en el mercado británico, crearon The Lerez Natural Mineral Water-Company con la exclusiva de la distribución y venta de las aguas en Inglaterra, Escocia, Irlanda, Estados Unidos, Canadá, África, Australia, Nueva Zelanda, India y Egipto. Hacia 1907, el éxito inicial les condujo a ampliar el millón y medio de botellas anuales acordadas a dos millones debido a los numerosos pedidos que atendían. Según el Diario de Pontevedra

24 Evidentemente, la diferente composición química de las aguas influye en sus posibilidades de embotellamiento, 0 bien como aguas terapéuticas 0 bien como aguas de mesa, 0 ambos casos.

25 Piernas et al., 1997, 25-45, 65-148. Piernas, 2009, 44-45. del mismo año, salían para Inglaterra y América del Sur unas cinco mil botellas diarias de Aguas del Lérez $^{26}$.

En general, el uso terapéutico del agua primó frente al consumo como agua de mesa hasta bien avanzado el siglo XX. Debemos tener en cuenta que su origen mineromedicinal, y por tanto su vinculación balnearia, ofrecían una garantía de calidad y actuaba como enseña distintiva de las aguas, un rasgo que todavía permanece en el sector -y el imaginario colectivo- y que resulta necesario mantener como elemento diferenciador para el consumidor final. No obstante, la dictadura de Primo de Rivera supuso un gran paso hacia la consideración de las aguas mineromedicinales como bebida de uso común -desligada de fines terapéuticos- dado que el real decreto de 12 de febrero de 1925 permitió su distribución en régimen de libertad comercial ${ }^{27}$ :

\footnotetext{
"las aguas minero-medicinales declaradas de utilidad pública o autorizada la venta embotellada, podrán venderse libremente, tanto en farmacias y droguerías como en los depósitos autorizados", entendiendo por tales "todo establecimiento mercantil que satisfaga los tributos correspondientes y cuente con la debida autorización del propietario de las aguas"28.
}

La Guerra Civil supuso un duro golpe para las embotelladoras a través de la intervención de los balnearios, establecimientos a los que todavía permanecían ligadas y que durante la contienda se vieron transformados en hospitales militares, cuarteles o polvorines, lo que conllevó en numerosas ocasiones el cierre total 0 parcial de la actividad balnearia y, por ende, envasadora. Los balnearios de Mondariz, Caldas de Nocedo, Miranda de Ebro, Marmolejo, Caldas de Oviedo, Alzola y Molinar de Carranza, entre otros, se transformaron en hospitales de sangre. Otros fueron utilizados para acuartelamiento de las tropas - Caldas de Besaya, Caldas de Oviedo, Borines, La Isabela, Corconte, Castillo y Elijebeitia y Caldas de Nocedo, entre otros- o para sedes del ejército (Carabaña, San Juan de Azcoitia). Algunos sufrieron graves bombardeos al estar emplazados en lugares estratégicos, como los de Montagut, Paracuellos, Alceda, Caldas de Besaya y Paraíso. Muchos se convirtieron en prisiones -los de Quinto y Santa Teresa-, albergues (La Puda, Molinar de Carranza, sede de las brigadas internacionales) e incluso almacén de municiones (Montagut). Otros se transformaron tras la contienda en seminarios religiosos, cuyos centros originales habían sido destruidos, como los de Molinar de Carranza, Zuazo, Villaro, Rius, Ontaneda y Onteniente. Finalmente, algunos otros acabaron por asimilarse a sanatorios para atender a los afectados de tuberculosis, una enfermedad que había conseguido controlarse en los años treinta, pero que regresó adherida a la miseria de la posguerra. En este grupo entrarían, entre otros, los de Panticosa, Cardó, Santa Teresa, Boñar y Busot ${ }^{29}$.

Los establecimientos supervivientes tuvieron que enfrentarse a la precaria situación económica del país en la posguerra, lo que no favoreció la rápida recuperación del sector. La mayoría de instalaciones habían quedado dañadas tras el conflicto y/o

\footnotetext{
26 Pereira, 2009, 126-138. Existe constancia de pedidos por parte de la Casa Real inglesa y de la Casa Real española.

27 Alonso, Vilar y Lindoso, 2012.

28 Gaceta de Madrid, 21 de abril de 1927, 111, 700-701.

29 Sánchez Ferré, 2001, 75-87.
} 
La explotación empresarial de las aguas mineromedicinales: la industria del agua embotellada en España (1875-2013)

Tabla 4. Principales envasadoras de agua en España, 1943

\begin{tabular}{|l|l|l|l|c|}
\hline Provincia & Localidad & Establecimiento & Manantial & Num. Bot. \\
\hline Gerona & Caldas de Malavella & Vichy Catalán & Vichy Catalán & 3.455 .000 \\
\hline Madrid & Carabaña & Carabaña & La Favorita & 3.155 .695 \\
\hline Palmas (Las) & Firgas & Fuente Agria & La Ideal & 2.180 .980 \\
\hline Pontevedra & Mondariz & Balneario de Mondariz & Gándara-Troncoso & 1.114 .455 \\
\hline Palmas (Las) & Valsequillo & San Roque & San Roque & 1.100 .000 \\
\hline Pontevedra & Mondariz & Fuente del Val & Fuente del Val & 1.000 .000 \\
\hline Palmas (Las) & Teror & Fuente Agria & Fuente Agria & 960.160 \\
\hline Gerona & Caldas de Malavella & Agua Imperial & Els Bullidors & 730.000 \\
\hline Oviedo & Piloña & Balneario de Bolines & La Victoria & 450.000 \\
\hline Guipúzcoa & Lizarza & Insalus, S.A. & Insalus & 315.764 \\
\hline
\end{tabular}

Fuente: EME, 1943.

necesitaban inversiones renovadoras. Por otro lado, la demanda cayó en picado en un marco de escasez, carestía y racionamiento. La autarquía tampoco favoreció la llegada de capitales extranjeros ni la importación de nuevas tecnologías que permitieran importantes avances como en otros países europeos. Dentro de este contexto, algunos balnearios acabaron por languidecer hasta paralizar su actividad, solo en algunos logró sobrevivir la actividad embotelladora. Así sucedió, por ejemplo, con el Gran Hotel Balneario de Mondariz y el Gran Hotel Balneario de Solares que acabaron por cerrar sus puertas al público. En el caso de Lanjarón el declive se agravó cuando sor Matilde Carrillo decidió donar su parte del balneario a su Congregación de las Hijas de la Caridad de San Vicente de Paul, y estas, a su vez, en 1940 le compraron su parte al hermano José Carrillo, haciéndose dueñas de las "Aguas y Baños minero medicinales de Lanjarón". Las instalaciones se marchitaron hasta que Manuel Gallardo Torrens compró a la Orden el establecimiento en 1946.

Las empresas con planta embotelladora independiente o con suficiente entidad respecto a la actividad balnearia soportaron mejor el envite de la posguerra. Este fue el caso de Carabaña, Firgas, Vichy Catalán o Aguas de Mondariz-Fuente del Val. A su favor jugó el deficiente suministro de agua y la escasez de medicinas en un contexto de agravamiento de enfermedades como el tifus o la tuberculosis, que las convirtió en "remedio" natural. Además, dado que se trataba de una industria intensiva en trabajo y poco mecanizada que no dependía del exterior para obtener la materia prima y empleaba envases de vidrio retornables, disfrutaba de una "ventaja" competitiva en un contexto de recortes energéticos y restricciones a la hora de importar. En consecuencia, la venta del producto permaneció ligada a las propiedades terapéuticas del mismo y pese a la libertad comercial decretada anteriormente se vendía sobre todo en farmacias. Así, la Ley de Bases de Sanidad de 1944 reconocía todavía a las aguas como "artículos de uso medicinal"30.

Una de las pocas estadísticas publicadas en la época sobre la industria del embotellado recoge en torno a 43 manantiales que embotellaban sus aguas hacia el año 1943; de estas unas diez vendían en torno al 95\% de las botellas producidas en el país (Ta-

30 BOE, 26 de noviembre de 1944, base 16, 8921. bla 4$)^{31}$. A pesar de las mencionadas adversidades, en la década de 1940 comenzó a superarse de manera excepcional la barrera de los diez millones de botellas anuales vendidas en territorio español. Este crecimiento estaba protagonizado por algunos balnearios que envasaban todavía con métodos tradicionales. Se trataba de establecimientos como los de Las Palmas (Islas Canarias), Girona (Cataluña), Guipúzcoa (País Vasco), o los de Mondariz, Balneario del Lérez y Cabreiroá (Galicia), que registraron algunas de las cifras de ventas más considerables de esta etapa.

Respecto a Vichy Catalán, confiscada durante la Guerra Civil, una vez que los accionistas recuperaron la empresa, esta reinició su actividad industrial en los años cuarenta. Durante este difícil periodo la sociedad anónima gerundense se transformó en el referente del sector de aguas envasadas en España con continuas renovaciones en su infraestructura en los años subsiguientes. Cuando la dictadura eliminaba los últimos residuos autárquicos e impulsaba una mayor apertura comercial y política a finales de la década de 1950, constituía la primera firma española en la que operaba un tren automático de lavar, rellenar, tapar y etiquetar importado de Alemania. Precisamente, en la década de 1960, las necesidades de incrementar la capacidad de producción para cubrir la creciente demanda desembocaron en la inversión en nuevos trenes de embotellado, con lo que la empresa resultó pionera en la automatización del proceso de embotellado. De esta manera, producían unos doce millones de botellas hacia 1960 y unos cuarenta y tres millones en $1970^{32}$.

En segunda y tercera posición respectivamente, se encontraba el establecimiento madrileño de Carabaña -que explotaba el manantial La Favorita-, y el de Fuente Agria -cuya base era el manantial canario La Ideal-. En la década de 1940, las aguas de San Roque y La Ideal, explotada por Aguas Minerales de Firgas, lideraron el crecimiento de las aguas canarias, llegando a absorber el $90 \%$ de la producción en el año 1955. Sintomáticamente, desde el año 1946 las estadísticas canarias comenzaron a separar las aguas de mesa de aquellas destinadas a usos terapéuticos, reconociendo de esta manera una naciente independencia del

31 El número de botellas envasadas en dichos manantiales ascendió a 14.462.054, siendo el número total de botellas en el año de 1943, 15.302.955 (EME, 1943).

32 Piernas et al., 1997, 25-45, 65-148. Piernas, 2009, 44-45. 
subsector de aguas envasadas del termal ${ }^{33}$. En conjunto, el Norte peninsular y las Islas Canarias concentraban a las mayores envasadoras del momento. El desmantelamiento de las barreras que protegían el mercado español y la mayor disponibilidad de crédito para invertir permitieron más tarde modernizar tecnológicamente la industria mientras aumentaba su capacidad de producción. Sin embargo, el sector presentaba todavía una fuerte atomización empresarial y, en pocos casos, sus mercados superaban el ámbito local o regional, ya no digamos internacional.

LA SUPERACIÓN DEL PARADIGMA TERMAL.

NuEVAS ESTRATEGIAS EMPRESARIALES

DE LA INDUSTRIA DEL AGUA EMBOTELLADA, 1959-2013

A finales de la década de 1950, la política económica de la dictadura transitaba desde la autarquía hacia un mayor aperturismo económico y político ${ }^{34}$. El giro económico se consolidó con el Plan de Estabilización (1959), que supuso la aceptación por parte de la dictadura de la economía de mercado preponderante en el mundo occidental. Tal y como mencionamos en el epígrafe anterior, el desmantelamiento de las barreras que protegían el mercado español y la mayor disponibilidad de crédito para invertir permitieron mecanizar la industria del agua embotellada, a la vez que aumentaron su capacidad de producción. El masivo éxodo rural de población hacia las ciudades y la expansión del suministro público de agua mejoraron las condiciones sanitarias de los habitantes. Por otro lado, el incremento del poder adquisitivo y el boom del turismo de "sol y playa" en la década de 1960 impulsaron cambios en las pautas de consumo. En paralelo, el agua embotellada dejó de ser utilizada como remedio terapéutico para convertirse de manera progresiva en un referente de vida saludable. Sin embargo, la estructura empresarial del sector permaneció atomizada: una constelación de numerosas pequeñas y medianas empresas dispersas por el territorio dirigían sus productos al mercado regional ${ }^{35}$.

Hasta la citada década, las aguas de Solares y Vichy Catalán constituyeron las aguas más vendidas en territorio peninsular. La primera en la categoría de aguas sin gas y la segunda en el segmento de aguas con gas. La sociedad anónima Vichy Catalán -de capital nacional y en manos de la familia Renart-Montalat en la actualidad- se especializó en la producción de agua mineral con gas y se transformó en el referente tecnológico del sector en España. Su papel pionero en la automatización se reforzó en la década de 1960 con nuevas inversiones impulsadas por la creciente demanda. En 1970, se había convertido en líder nacional en su área de negocio con casi la quinta parte de la cuota del mercado ${ }^{36}$. Tras un corto paréntesis de caída en sus ventas entre 1974 y 1977 en un contexto de crisis general, ampliaron su oferta de aguas minerales ante una competencia cada vez más fuerte. Además, desde finales del decenio, su ascenso, al igual que el de Font Vella -declarada oficialmente agua mineromedicinal en 1957-, se vio promovido por la debacle de otra de las grandes, Aguas de

\footnotetext{
33 EME, 1932-1955.

34 Siguiendo a Catalán, 2003.

35 Revista Alimarket, 140, 2001, 249-269.

36 Piernas, Pous y De Planell, 1997, 25-45, 65-148. Piernas, 2009, 44-45.
}

Solares - marca con una cuota de mercado del $65 \%$ a mediados de 1970 y herida de gravedad por problemas de contaminación en sus aguas ${ }^{-37}$. Desde entonces, la catalana comenzó una política expansiva ampliando las zonas de venta y adquiriendo otras compañías. Esta estrategia culminó con la constitución del grupo Vichy Catalán en la década de 1990 (Tabla 1) 38 .

A partir de la década de 1960, la mayoría de las plantas de embotellado españolas que seguían ligadas a las estaciones termales se independizaron de sus casas matrices aquejadas de una fuerte pérdida de clientes. Por ejemplo, los establecimientos termales de Fontenova y Sousas (Verín-Ourense) cerraron sus puertas de manera definitiva a comienzos de la década de 1960 mientras que se mantenía y relanzaba la explotación comercial de sus aguas envasadas. La fábrica de envasado de Cabreiroá, otra de las marcas emblemáticas del sector, siguió situada al lado de su famoso hotel-balneario pero sin perspectivas de que este se reflotase y se transformó en sociedad anónima en el año 1973 (Tabla 1). El esplendor de la estación termal de Fuencaliente de Solares -cuya tradición balnearia se remonta al siglo XVIII- se apagó durante la Guerra Civil y cerró sus puertas en 1976. Su agua mineral embotellada sobrevivió y superó con el tiempo la crisis experimentada en 1977-1978, provocada por una terrible contaminación bacteriana en el envasado. La factoría se cerró temporalmente, pasó a manos públicas y una década después se reprivatizó y fue adquirida por el empresario de la industria del café, Ángel Añíbarro (Tabla 1). Desde entonces, resurgió de sus cenizas y la envasadora, Manantial de Fuencaliente, S. A., se encuentra entre las principales del mercado, aunque lejos de las posiciones líderes de antaño ${ }^{39}$. Asimismo, el Gran Hotel de Mondariz fue pasto de las llamas a principios de la década de los 1970 pero las Aguas de Mondariz y Fuente del Val sobrevivieron y se fusionaron en los ochenta (Tabla 1$)^{40}$.

En paralelo, la ley 22/1973 de Minas estableció el funcionamiento normativo de las aguas nacionales. Según este texto, la puesta en explotación de los manantiales debía contar con el permiso del Ministerio de Industria, previa declaración de la condición mineral de las aguas de la Dirección General de Minas y el informe positivo de la Dirección General de Sanidad, que determinaría la composición química de las aguas ${ }^{41}$. Por tanto, la industria permanecía sometida a la jurisdicción de diferentes organismos públicos, una reminiscencia decimonónica que caracteriza el desarrollo del sector. Más adelante, el marco regulador de las aguas minerales embotelladas en España adoptó las directivas comunitarias que, desde 2010, estipularon una clara separación legal entre la explotación y comercialización de aguas

\footnotetext{
37 Green y Green, 1986, 90-97.

38 Piernas, Pous y De Planell, 1997, 65-175. Piernas, 2009, 116-117 y 323347. Anónimo, 2006, 5.

39 http://www.aguadesolares.com; http://www.mercadocalabajio.com/2010/ 06/agua-solares-elagua-mineral-mas.html; http://www.hotelbalneariosolares. es/quienes.html (consulta realizada el 11 de abril de 2012); El País, 20 de abril de 1977; 6 de mayo de 1977; 14 de mayo de 1977; 7 de julio de 1977; 4 de noviembre de 1978; 28 de diciembre de 1983; 27 de septiembre de 1986; 4 de enero de 1987; 12 de mayo de 1987; 18 de junio de 1999 (consulta realizada el 12 de abril de 2012). Revista Alimarket, 250, 2011, 204-205.

40 Véase Alonso, Lindoso y Vilar, 2011, capítulo dedicado a Mondariz.

41 BOE, 24 de julio de 1973, 176, 150 y ss.
} 
La explotación empresarial de las aguas mineromedicinales:

la industria del agua embotellada en España (1875-2013)

minerales naturales y aguas de manantial envasadas para consumo humano ${ }^{42}$.

En el último cuarto de siglo, el avance del sector de aguas envasadas en España resultó extraordinario. La producción nacional de agua embotellada se centuplicó entre 1962 y 2013 -de 45 millones de litros a 4.600-43. Por término medio, los litros de agua envasada producidos en España se multiplicaron casi por diez entre 1975 y 2009 tras alcanzar el máximo de la producción en el año 2006 (Tabla 5). Dicho incremento se logró inicialmente mediante la apertura de nuevos manantiales con sus plantas de embotellado hasta alcanzar los 117 en el año 1997, una cifra que apenas ha variado en la actualidad ${ }^{44}$. Así, la Asociación Nacional de Empresas de Aguas de Bebida Envasada (ANEABE) señala que existen en torno a un centenar de empresas en el sector frente a las 43 envasadoras activas durante la posguerra civil 45 . El proceso no resultó lineal. Tras una corta crisis en el año 199646, el sector se recuperó con fuerza y creció a tasas altísimas hasta 2006, cuando la madurez del mercado y la posterior crisis mundial -y española - que todavía estamos viviendo ralentizaron su crecimiento.

Tabla 5. Producción de agua embotellada en España, 1975-2010 (media en millones de litros)

\begin{tabular}{|l|r|}
\hline \multicolumn{1}{|c|}{ Año } & \multicolumn{1}{c|}{ Media } \\
\hline $1975-1979$ & 558 \\
\hline $1980-1984$ & 851 \\
\hline $1985-1989$ & 1.306 \\
\hline $1990-1994$ & 2.328 \\
\hline $1995-1999$ & 3.088 \\
\hline $2000-2004$ & 4.587 \\
\hline $2005-2009$ & 5.571 \\
\hline 2013 & 4.600 \\
\hline
\end{tabular}

Fuente: para 1977-2002, ANEABE, Libro Blanco..., y Baeza, López y Ramírez, 2001, 57; año 2013: estimación publicada en Revista Alimarket, 283, 2014, 206 221. Para los años 2003-2006, Estadisticas alimentarias de España, 69. El resto, Lindoso y Vilar, 2014.

Asimismo, desde finales de 1970, la automatización de los procesos, en la que Vichy Catalán había sido pionera, se extendió a otras empresas. De este modo, el sector experimentó cambios tecnológicos transcendentales al incorporar líneas automatizadas en el envasado y sustituir los envases de vidrio por los de plástico.

42 Real decreto 1798/2010, de 30 de diciembre, véase http://www.aesan. msc.es/AESAN/web/cadena_alimentaria/seccion/gestion_aguas_envasadas.sht$\mathrm{ml}$ (consulta realizada el 15 de noviembre de 2013). Por otro lado, cabe destacar que la ley 14/1986, de 25 de abril, General de Sanidad, ya no incluye, como sus predecesoras una referencia específica al agua de manantial como artículo de uso exclusivamente medicinal, lo que pone de manifiesto su transformación en un bien de consumo habitual.

43 López de Azcona, 1963, 32 y Revista Alimarket, 283, 2014, 206-221.

44 Revista Alimarket, 107, 1998, 161-179 y 206, 2007, 221-243.

45 EME, 1943-1944.

46 Revista Alimarket, 107, 1998, 161 y ss., califica de atípica la citada crisis ocasionada por la abundancia de lluvias y por la coyuntura económica. En 1997, el mercado retomó la trayectoria anterior.
Precisamente, el buen comportamiento del sector tras el ligero bache de 1996 propició la realización de cuantiosas y continuas inversiones. Se amplió la capacidad productiva de sus plantas, sobre todo para los formatos PET, los más demandados ${ }^{47}$. El tradicional envase cristalino tendió a reservarse para la hostelería y para mejorar la imagen de marca, modernizando y diferenciando las diferentes enseñas con nuevos diseños, colores, etiquetas, etc. ${ }^{48}$

De manera simultánea, este próspero negocio empezó a atraer a las multinacionales de la industria del agua. Los grandes grupos empresariales franceses y suizos de alimentación y bebidas aterrizaron en la década de 1970 y a continuación, los italianos y estadounidenses. En 1974 Font Vella pasó a formar parte del BSN group, que en 1994 pasó a denominarse Danone group. Durante estos años se convirtió en el agua con mayor cuota de mercado en España. Por otro lado, Eycam, la filial del grupo Perrier en España, adquirió San Narciso, Imperial y una participación en Agua de Viladrau en 1979. Asimismo, Nestlé compró parte del agua del Valle de Cardó (Tarragona) ${ }^{49}$. En consecuencia, el mapa empresarial de la industria del agua sufrió una profunda transformación en la década de los setenta con la penetración de multinacionales que perseguían atractivos mercados emergentes. No obstante, la salida al exterior de la industria del agua envasada nacional resultaba reducida. Debemos considerar que la mayoría de la producción española de aguas minerales era, y es, consumida en el interior del país, donde existe una indudable preferencia por las aguas sin gas a diferencia del pionero modelo francés y del alemán ${ }^{50}$. No poseemos datos seriados de la exportación de las aguas españolas antes de la década de los noventa. Según las cifras que nos ofrece el servicio de Eurostat para el año 1997, esa variable representaba un diminuto 0,88\% de la cantidad producida. En los años siguientes, tuvo lugar una modesta mejoría. Así, cuando la gran crisis mundial empezaba a golpear, las ventas internacionales registraban un 1,7\% de la producción en el año 2008. Sin embargo, actualmente, ese mínimo porcentaje se ha contraído por debajo de las cifras del decenio de 1990 (Tabla 6) $)^{51}$. De esta manera, el modelo productivo español se asemeja más al italiano, salvo en el aspecto clave de la internacionalización $^{52}$. La incipiente internacionalización de las aguas españolas, entendiendo por esta un primer paso ligado a las ventas exteriores, se había cortado desde la Guerra Civil. Aquellas exportaciones de aguas de finales del siglo XIX hacia Hispanoamérica 0 Europa celebradas con asombro por la prensa de la época no se sostuvieron a medio plazo.

Asimismo, debemos tener en cuenta una característica de la estructura empresarial del sector de aguas español presente desde los orígenes de la industria y que no actúa precisamente como barrera de entrada en el sector: su mencionada atomización. Las firmas explotaban diversos manantiales dispersos por el territorio

47 Hacia 2004 , el $81 \%$ de los envases se fabricaban con PET, materia prima que a finales de la década de 1980 tenía una participación residual sobre el resto de los envases, véanse Revista Alimarket, 173, mayo de 2004, 255-277; 140, mayo de 2001, 249-269; 107, 1998, 161-179.

48 Revista Alimarket, 140, 2001, 249-269.

49 Green y Green, 1986, 90-97.

50 Lindoso y Vilar, 2014.

51 Revista Alimarket, 283, 2014, 206-221.

52 Lindoso y Vilar, 2014. 
Tabla 6. Comercio exterior español de agua mineral y agua gaseada, 2008-2013

\begin{tabular}{|c|c|c|c|c|c|}
\hline España & Exportaciones & Importaciones & Exportaciones & Importaciones & Saldo \\
\hline Año & Miles kilos & Miles kilos & Miles euros & Miles euros & Miles euros \\
\hline 2008 & 94.368 & 43.737 & 12.032 & 12.378 & -345 \\
\hline 2009 & 69.703 & 25.108 & 9.448 & 7.128 & 2.319 \\
\hline 2010 & 86.528 & 23.551 & 10.946 & 7.709 & 3.237 \\
\hline 2011 & 78.747 & 24.040 & 11.702 & 9.462 & 2.240 \\
\hline 2012 & 40.698 & 30.123 & 9.923 & 9.923 & -827 \\
\hline 2013 & 31.713 & 32.552 & 8.750 & 12.451 & -3.700 \\
\hline
\end{tabular}

Fuente: Base de datos de Comercio exterior (http://aduanas.camaras.org/, consulta realizada el 9 de mayo de 2014).

y sus ventas se circunscribían a mercados locales o como mucho regionales, pese a la presencia de algunas grandes plantas envasadoras ${ }^{53}$. Debemos reseñar también que si bien hoy en día el sector aún continúa atomizado, su grado de concentración ha aumentado desde el último cuarto del siglo XX. Ocho empresas absorbían alrededor del $60 \%$ de las ventas a finales de febrero de 2014 (Tabla 7). Además, la década de 1980 conoció otro fenómeno que reforzó el prestigio de las aguas mineromedicinales e impulsó su renacimiento tras el periodo de languidecimiento de la posguerra civil. Se trata de las políticas públicas de promoción turística que incentivaron la recuperación de antiguos balnearios, contribuyeron a la rehabilitación y fomentaron la afluencia de visitantes con políticas de marketing y planes de ocio como el IMSERSO. De esta forma, algunas instalaciones iniciaron una segunda juventud tras ver rehabilitadas sus instalaciones y su clientela, que ahora trataba de cubrir sus necesidades de bienestar más que las de salud de antaño ${ }^{54}$. Una de las remodelaciones más recientes

Tabla 7. Reparto del mercado de aguas envasadas por empresas, 31 de febrero 2014 (en porcentaje y totales en millones)

\begin{tabular}{|l|c|c|}
\hline \multicolumn{1}{|c|}{ Empresa } & $\begin{array}{c}\text { Litros } \\
\text { Porcentaje }\end{array}$ & $\begin{array}{c}\text { Euros } \\
\text { Porcentaje }\end{array}$ \\
\hline Aguas Font Vella y Lanjarón & 13,1 & 22,0 \\
\hline Agua Mineral San Benedetto & 8,4 & 5,2 \\
\hline Nestlé Waters & 8,2 & 10,2 \\
\hline Calidad Pascual & 7,5 & 12,0 \\
\hline Mahou-San Miguel & 2,8 & 5,8 \\
\hline Gestión Fuente Liviana & 2,0 & 2,4 \\
\hline Coca Cola & 1,8 & 1,9 \\
\hline Vichy Catalán & 0,9 & 1,1 \\
\hline Resto & 12,9 & 10,3 \\
\hline MDD & 42,4 & 29,1 \\
\hline Total de litros y euros & 3.239 & 702 \\
\hline
\end{tabular}

Fuente: Revista Alimarket, 283, 2014, 206-221.

53 La atomización se observaba sobre todo en cuanto a marcas porque, en general, había muy pocas enseñas que tuviesen una cuota importante de mercado y una imagen diferenciada y consolidada. Por ello, para el consumidor, el precio es uno de los principales factores a la hora de elegir el producto, véase Revista Alimarket, 140, 2001, 249-269.

54 Alonso, Lindoso y Vilar, 2011, véanse los dos primeros capítulos del libro. ha sido la del balneario de Carabaña, rehabilitado por Hoteles Foxá del grupo Torme e inaugurado en 2010 (Tabla 1) 15 $^{55}$.

Entretanto, las grandes multinacionales extranjeras adquirían de manera progresiva mayores cuotas de mercado en la industria del agua embotellada. A la francesa Danone y a la suiza Nestlé, se le añadieron empresas italianas, norteamericanas y, en menor medida, holandesas y portuguesas en la década de 1990. A mediados del decenio, Agua Mineral San Benedetto, filial de su homónima italiana, desembarcó en España ${ }^{56}$. La firma familiar Acqua Minerale San Benedetto S.p.A, fundada en 1956 para embotellar las aguas de dos surgencias venecianas, inició una estrategia de internacionalización a partir de la década de $1970^{57}$. Pero en pocos países como España ha instalado plantas de producción propias. En el mercado peninsular, su vía de crecimiento se sustentó en el ejercicio de una política de precios por envase por debajo de la media sectorial; de esta manera, consiguió encuadrarse entre las cinco primeras envasadoras a comienzos del siglo $X X I^{58}$. Coca-Cola también se introdujo con éxito bajo la marca de Aquabona, que recoge aguas embotelladas de distintos manantiales repartidos por el territorio. Apoyada en la importante red de distribución de sus franquiciados, consiguió en poco tiempo colocarse entre los diez primeros grupos por volumen comercializado y se convirtió en un fuerte rival para Vichy, Pascual y las veteranas Danone y Nestlé. Estas lograron optimizar su logística y sus costes de distribución, siguiendo por lo general un modelo de negocio basado en la toma de manantiales para las diferentes zonas geográficas. Se trataba de competir obteniendo centros de producción en distintos puntos con los que fortalecer su cobertura de mercado ${ }^{59}$. Operaciones empresariales de compra-venta y de creación de nuevas plantas jalonaron los años posteriores a la entrada de las grandes corporaciones mundiales.

¿Quién domina el mercado español de aguas en la actualidad? Desde finales de la década de 1990, la multinacional francesa Danone lidera el mercado de aguas español cuando se transformó en la primera empresa del sector por volumen de ventas, seguido del

55 Desafortunadamente, el grupo Torme ha entrado en proceso de liquidación, véase Cinco Días, 20 de junio de 2013.

56 Revista Alimarket, 107, 1998, 161-179 y 129, 2000, 199-217.

57 www.smigroup.it/smi/repository.../SAN\%20BENEDETTO_ES.pdf (consulta realizada el 30 de mayo de 2014).

58 Aproximadamente entre un 13 y un $15 \%$ de su volumen se destina a marcas de distribución, véanse Revista Alimarket, 129, 2000, 199-217; 151, 2002, 213-233. 59 Revista Alimarket, 173, 2004, 255-277; 184, 2005, 235-256; 206, 2007, $221-243$. 
La explotación empresarial de las aguas mineromedicinales: la industria del agua embotellada en España (1875-2013)

Tabla 8. Principales compañías de agua embotellada en España y sus principales marcas, 1999-2013 (volumen en millones de litros y ventas en millones de euros)

\begin{tabular}{|c|c|c|c|c|c|c|}
\hline Empresa & $\begin{array}{l}1999 \\
\text { (vol.) }\end{array}$ & Marcas & Empresa & $\begin{array}{l}2013 \\
\text { (vol.) (1) }\end{array}$ & $\begin{array}{l}2013 \\
\text { (vtas.) }\end{array}$ & Marcas \\
\hline Font Vella, S. A. (Danone) & 500 & Font Vella, Fonter, Font Picant & $\begin{array}{l}\text { Aguas Font Vella y } \\
\text { Lanjarón, S. A. }\end{array}$ & $660^{*}$ & $195^{*}$ & $\begin{array}{l}\text { Font Vella, Fonter, Lanjarón, } \\
\text { F.V.Sensación }\end{array}$ \\
\hline Grupo Vichy Catalán, S. A. & 366 & $\begin{array}{l}\text { Vichy Catalán, Fontdor, Monda- } \\
\text { riz, Font del Regás }\end{array}$ & $\begin{array}{l}\text { Agua Mineral San } \\
\text { Benedetto, S. A. }\end{array}$ & 622 & $70,5(+, 2)$ & $\begin{array}{l}\text { Fuente Primavera, Font Natura, San } \\
\text { Benedetto, Fuencisla }\end{array}$ \\
\hline $\begin{array}{l}\text { Aguas de Lanjarón, S. A. } \\
\text { (Danone) }\end{array}$ & 210 & Lanjarón, Fonteforte, S.Vicente & $\begin{array}{l}\text { Calidad Pascual, S. } \\
\text { A. U. }\end{array}$ & $435^{*}$ & $125^{*}$ & Bezoya, Pedras Salgadas \\
\hline $\begin{array}{l}\text { Aguas Minerales Pascual, } \\
\text { S. A. }\end{array}$ & 246 & Bezoya, Zambra, Cardó & $\begin{array}{l}\text { Nestlé Waters España, } \\
\text { S. A. }\end{array}$ & $420^{*}$ & 72,1 & $\begin{array}{l}\text { Nestlé Aquarel, Viladrau, San Pelle- } \\
\text { grino, Perrier }\end{array}$ \\
\hline $\begin{array}{l}\text { Agua Mineral San Bene- } \\
\text { detto, S. A. }\end{array}$ & 169 & Fuente Primavera & $\begin{array}{l}\text { Grupo Vichy Catalán, } \\
\text { S. A. }\end{array}$ & $370^{*}$ & $102^{*}(+)$ & $\begin{array}{l}\text { Vichy Catalán, Font d’Or, } \\
\text { Mondariz, Font del Regás, } \\
\text { Monte Pinos }\end{array}$ \\
\hline $\begin{array}{l}\text { Gestión Fuente Liviana, } \mathrm{S} \text {. } \\
\text { L. (Forlasa) }\end{array}$ & 180 & Fuente Liviana & Grupo Font Agudes & 282 & 25 & $\begin{array}{l}\text { Font Agudes del Montseny, } \\
\text { Font De's Teix, Agua Doy, } \\
\text { Virgen del Camino/ Fuentedona }\end{array}$ \\
\hline $\begin{array}{l}\text { Eycam-Perrier, S. A. } \\
\text { (Nestlé) }\end{array}$ & 170 & $\begin{array}{l}\text { Viladrau, Peñaclara, San Narciso, } \\
\text { Aquarel }\end{array}$ & $\begin{array}{l}\text { Aquabona (Coca-Cola } \\
\text { Iberian Partners) }\end{array}$ & $230^{*}$ & $27^{*}(3)$ & Aquabona \\
\hline $\begin{array}{l}\text { Balneario y Aguas de Solán } \\
\text { de Cabras, S. A. (Damm) }\end{array}$ & 146 & Solán de Cabras & $\begin{array}{l}\text { Aguas de Solán } \\
\text { de Cabras, S. A. }\end{array}$ & $195^{*}$ & $47^{*}$ & $\begin{array}{l}\text { Solán de Cabras, Sierra Natura, } \\
\text { Sierra de Jaén, Fuente Fría }\end{array}$ \\
\hline $\begin{array}{l}\text { Aguas minerales de Firgas, } \\
\text { S. A. }\end{array}$ & 92 & La Ideal II, San Antón & Aguas de Cortes, S. A. & 176,3 & 13,5 & Agua de Cortes \\
\hline Fontaga, S. A. & 88 & Aigua de Ribes & Grupo Damm & $150^{*}$ & $19,7^{*}$ & $\begin{array}{l}\text { Fuente Liviana, } \\
\text { Fuente del Marquesado, Veri }\end{array}$ \\
\hline
\end{tabular}

* estimación, n.d.; (+), se incluyen otras líneas de negocio en la facturación; (1) En muchos casos el volumen comercializado incluye el envasado en bidones de 18,9 020 litros para el canal HOD (oficinas y colectividades), no se han incluido las que solo trabajan esta especialidad; (2) Las ventas incluyen los ingresos por la comercialización de refrescos e isotónicas, los volúmenes reflejados son solo de agua mineral con y sin gas ; (3) Las ventas reflejadas provienen de la facturación a distribuidores, Bonaqua cambió su nombre por Aquabona en 2005. Fuentes: Revista Alimarket, 140, 2001, 249-253; 283, 2014, 206-221.

grupo independiente español Vichy Catalán. Más de una década después, Danone conserva el primer puesto tras fusionar Fontvella y Lanjarón, mientras tanto Vichy Catalán ha retrocedido hasta la quinta posición. Por encima del grupo español, se encontraban las filiales españolas del grupo italiano San Benedetto y Nestlé y un grupo nacional, el Grupo Leche Pascual (Tabla 8).

Font Vella y Lanjarón representaban el $17 \%$ del total de ventas en el mercado español en el año 2000, cuota que les situaba en una posición de liderazgo. En la actualidad, absorben un porcentaje inferior, el 13\%, aunque superior al de sus competidores (Gráfico 1$)^{60}$. Las aguas de Font Vella proceden de la localidad de Sant Hilari de Sacalm (Girona), conocida como la villa de las 100 fuentes $^{61}$. En la segunda mitad del siglo XIX, la localidad se convirtió en un centro balneario de importancia popularizando sus aguas ${ }^{62}$. A mediados de la década de 1920, esta pequeña empresa local ya vendía sus productos en Breda y posteriormente en Barcelona. En 1974, entró a formar parte del grupo BSN (Danone desde 1994). En 1993, incorporó Aguas de Lanjarón, S. A. y se-

60 A principios del siglo XXI, uno de los medios de la expansión internacional de la multinacional francesa consistía en la compra de participaciones en envasadoras regionales con una posición de liderazgo, sobre todo en mercados emergentes como Polonia, China, Indonesa y otros, véase Revista Alimarket, 140, 2001, 249-269.

61 La Esfera Empresarial, 11, marzo de 2004, http://issuu.com/laesfera1/ docs/11_industriacatalu_a (consulta realizada el 30 de mayo de 2014).

62 http://es.scribd.com/doc/61891022/10/Breve-historia-de-Font-Vella-yel-Grupo-Danone\#page=1 (consulta realizada el 4 de junio de 2014). paró la actividad balnearia de la envasadora. Ambas plantas se fusionaron bajo una sola denominación en 2006 pero mantienen sus marcas ${ }^{63}$.

La suiza Nestlé ascendió del séptimo puesto al cuarto entre 1999 y 2013 gracias a las ventas de Viladrau, San Pellegrino, Perrier y Nestlé Aquarel (Tabla 8)64. En 2000, había presentado de manera simultánea su primera marca paneuropea de agua de manantial bajo el nombre de Aquarel en Alemania, Francia, España, Portugal, Bélgica y Luxemburgo. La firma eligió dos manantiales: uno en Arbucies (Girona) para abastecer a los mercados español, portugués y del sur de Francia, y otro en Etalle (Bélgica), que nutriría a los restantes países ${ }^{65}$. Hacia 2013, Aquarel se había convertido en la tercera marca del mercado español por volumen de ventas tras Pascual (Gráfico 1).

Siguiendo una tendencia de descentralización de la producción, San Benedetto, Danone y Nestlé Waters realizaron una inmersión en la construcción de nuevas plantas para abastecer

63 http://www.ideal.es/granada/20061113/local/empresas-font-vella-lanjaron_200611131718.html (consulta realizada el 4 de junio de 2014). Sobre la historia de las aguas de Lanjarón, véanse Benavente y Castillo, 1999, 147-149. AA. VV, 1997. Benavente, Castillo y Cruz, 1999, 47. http://lanjaron.freehostia.com/ agua.html (consulta realizada el 4 de junio de 2014).

64 A finales de 1997, Nestlé se hizo con la envasadora San Pellegrino, convirtiéndose en líder del mercado italiano de aguas envasadas, véanse Revista Alimarket, 107, 1998, 161-179; 151, 2002, 213-233; 184, 2005, 235-256.

65 Revista Alimarket, 129, 2000, 199-217; 140, 2001, 249-269; 151, 2002, 213-233. 
Gráfico 1. Cuota de mercado del agua envasada por marca en España, 2000-2013 (millones de litros en \%)

Aguas, 2000

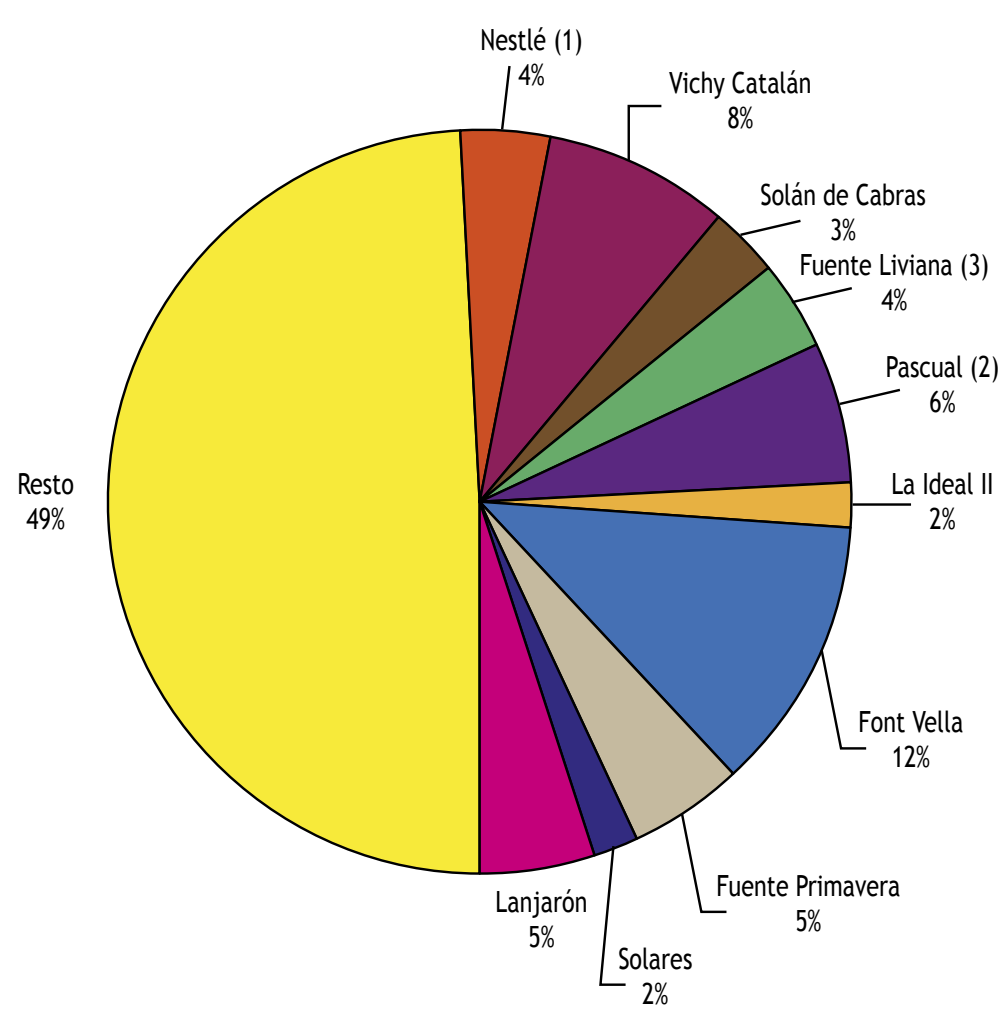

Aguas sin gas, 2013

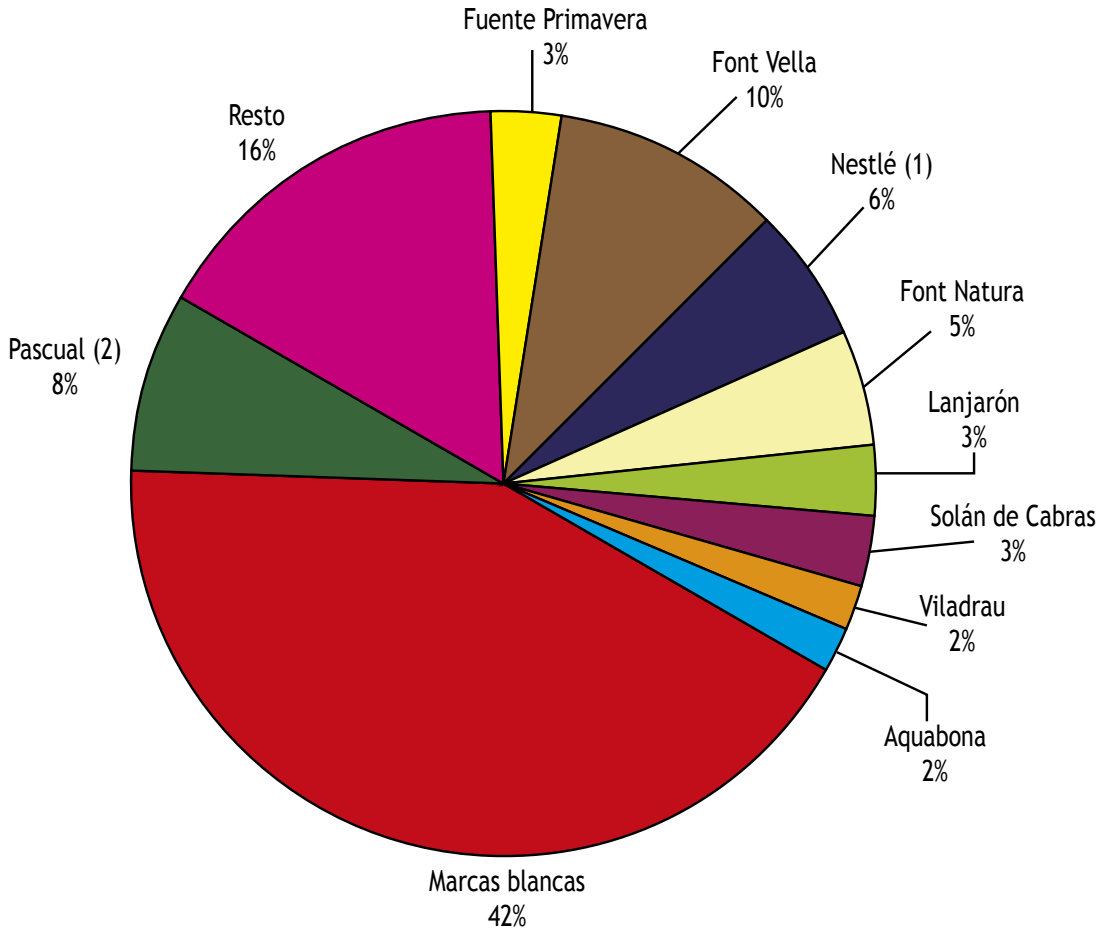

(1) Datos para Aquarel en 2010; (2) datos para Bezoya en 2010; (3) incluye Huerta del Marquesado en 2000. MDD: marca de distribuidor o marca blanca. Fuentes: Revista Alimarket, 140, 2001, 249; 283, 2014, $206-221$.

56 AGUA Y TERRITORIO, NÚM. 6, pp. 44-61, JULIO-DICIEMBRE 2015, ISSN 2340-8472, ISSN e 2340-7743, DOI 10.17561/at.v0i6.2809 
La explotación empresarial de las aguas mineromedicinales:

la industria del agua embotellada en España (1875-2013)

a la mitad sur o centro-sur peninsular ${ }^{66}$. Este comportamiento también se vio reflejado en las pequeñas y medianas empresas del sector que se atrevieron a ampliar la producción con un segundo manantial ${ }^{67}$. Tal y como mencionamos anteriormente, nuevas fuentes se pusieron en explotación ante las expectativas de rentabilidad que generaba el negocio de las aguas. Esta tendencia reforzó la superación del paradigma termal vigente hasta entonces dado que algunas de las nuevas plantas de embotellado no nacieron bajo el amparo de históricas estaciones termales. Frente a los manantiales tradicionales, muchas instalaciones modernas carecían de un cordón umbilical con los balnearios. En este caso, podríamos encuadrar a Calidad Pascual, S. A. U., grupo de "reciente" creación, comparado con aguas como las de Mondariz o Vichy, y segunda marca del mercado. La empresa se fundó en 1969, cuando un conjunto de empresarios de Burgos liderados por Tomás Pascual Sanz se hicieron cargo de una cooperativa láctea en quiebra en Aranda de Duero68. En 1974, bajo una estrategia de diversificación, la empresa obtuvo la concesión de explotación del manantial de agua mineral natural Bezoya en Segovia, su principal emblema. Más adelante, sacó al mercado una nueva línea de agua conocida como Pascual Nature, similar a Font Vella y Lanjarón, enseñas del grupo Danone con las que este había consolidado su primera plaza en el año $1997^{69}$.

En paralelo, varias compañías del sector de bebidas alcohólicas en España se introdujeron en la industria del agua. De hecho, el agua mineral natural Fuente Liviana, propiedad de Gestión Fuente Liviana S. L., acabó controlada por el grupo cervecero Damm; Hijos de Rivera (Estrella Galicia) se convirtió en accionista mayoritario de Cabreiroá. En el año 2011, el grupo andaluz Osborne vendió al gigante cervecero Mahou-San Miguel la totalidad del capital de la Sociedad Balneario y Agua Solán de Cabras, antes en manos del grupo Damm (Tabla 1) ${ }^{70}$. Por otro lado, Cervezas Alhambra se hizo cargo de la envasadora Sierra de Jaén (Sierra Natura) que llevaba varios años en crisis y arrastrando fuertes pérdidas. La envasadora jienense se traspasó al grupo holandés Heineken cuando adquirió la primera firma. En la actualidad forma parte de la cartera del grupo Mahou-San Miguel ${ }^{71}$. La ventaja competitiva de muchas de estas compañías radica en sus consolidadas redes de distribución de bebidas alcohólicas y azucaradas que les permiten obtener economías de alcance notables con la comercialización conjunta. El potencial de crecimiento de la de-

66 Revista Alimarket, 151, 2002, 213-233; 173, 2004, 255-277. El agua Aquafina de Pepsi no ha supuesto un producto competitivo para las empresas del sector de aguas en España dado que su condición de "agua tratada" no tiene muy buena acogida en los gustos del consumidor español.

67 Revista Alimarket, 151, 2002, 213-233.

68 Periódico El Mundo (ed.): "El empresario que levantó un imperio alimentario desde la nada", 23 de febrero de 2006 (consulta realizada el 26 de marzo de 2012).

69 Hoy en día, el grupo Pascual se mantiene en el mercado como una empresa familiar de capital $100 \%$ español, al igual que Vichy Catalán, véase Leche Pascual, Memoria de Responsabilidad Social, 2010 (http:/ / www.lechepascual.es/ docs/rsc/2010/01. Perfil.pdf, consulta realizada el 4 de junio de 2014).

70 Periódico El Mundo, 22 de marzo de 2009 (http://www.elmundo.es/suplementos/magazine/2009/495/1237378714.html, consultado el 26 de marzo de 2012); Periódico La Razón, 25 de febrero de 2011, consultado el 26 de marzo de 2012; Revista Alimarket, 250, 2011, 203-225.

71 Revista Alimarket, 151, 2002, 213-233; 173, 2004, 255-277; 283, 2014, 206-221. manda nacional despertó también el interés de grupos empresariales ajenos al sector alimentario: la Compañía Explotadora de Minas de Panticosa, sociedad controlada por el grupo inmobiliario Nozar adquirió los activos y la marca "Agua de Panticosa" de Embotelladora de Panticosa a finales de $2003^{72}$.

Una vez que las grandes empresas de bebidas se posicionaron en el sector, desarrollaron lo que los analistas denominan una estrategia "multimanantial-monomarca". Esta política empresarial ha consistido en la unificación de marcas en torno a múltiples manantiales, la optimización de la logística (los costes de distribución siguen siendo decisivos en el precio de venta final ${ }^{73}$ ), el matrimonio de algunas envasadoras con la MDD para impulsar su crecimiento y la mejora generalizada del producto (inversión en maquinaria y su flexibilidad para el lanzamiento de nuevos formatos y productos $)^{74}$. La mejora en los mecanismos de producción y distribución han resultado esenciales para afrontar la competencia creciente. De este modo, desde el punto de vista de los precios, el mercado de aguas quedó configurado en tres zonas: las de precio alto, las del grupo Font Vella, Vichy Catalán y Solán de Cabras que casi doblan los precios de sus rivales, marcas de alto valor añadido para el consumidor; las de precio medio, Aquarel, Viladrau, Fuente Liviana, Pascual Nature y Aquabona y algunas otras enseñas; y la de primer precio y especialistas en MDD, principalmente las de San Benedetto, Dialore y otros envasadores que por sus limitaciones comerciales y de competitividad no tuvieron más remedio que bajar sus precios para igualarlos a los de sus rivale $^{75}$. Las empresas de mayor dimensión se disputaban el arco mediterráneo, la franja más estratégica de la península por su alta densidad de población y por el elevado consumo per cápita de agua mineral durante todo el año: las Islas Baleares lideraron el consumo per cápita de agua envasada en los hogares españoles durante el año 2013 con 121 litros frente a la media española de $51^{76}$. Mientras, algunas pequeñas empresas no resistieron la intensa competencia y tuvieron que vender sus manantiales ${ }^{77}$.

En resumen, hacia 2013, cuatro de las diez primeras compañías del agua que operan en España son foráneas. El resto se reparte entre los grupos nacionales, algunos de mayor dimensión y ligados en ocasiones a la industria de bebidas alcohólicas (Tabla 8). Pero no resulta fácil mantener cuotas estables de mercado. Los liderazgos siguen apoyándose en la suma de cuotas locales con el fin de acceder a nuevos mercados ${ }^{78}$.

El boom del crecimiento de la industria del agua embotellada en España finalizó en el año 2006, cuando el sector tocó techo y las ventas comenzaron a descender (Gráfico 2). De momento, los datos no reflejan síntomas de recuperación. Los niveles de producción se revelan inferiores a los cifrados hace una década.

72 Ibídem, 140, 2001, 249-269; 151, 2002, 213-233; 173, 2004, 255-277.

73 El gasto en transporte, junto con la factura energética y los PET, conforman las partidas de gastos más notables para esta industria.

74 Uno de sus efectos ha sido que numerosas marcas regionales en manos de grandes envasadores desaparecieron para dar paso a enseñas a nivel nacional, manteniéndose únicamente las denominaciones de los manantiales, véase Revista Alimarket, 206, 2007, 221-243.

75 Ibídem, 184, 2005, 235-256; 195, 2006, 157-183; 206, 2007, 221-243.

76 Ibídem, 283, 2014, 206-221.

77 Ibídem, 239, 2010, 165-195.

78 Ibídem, 129, 2000, 199-217. 
Gráfico 2. Evolución de la producción de aguas envasadas en España, 2003-2013 (millones litros)

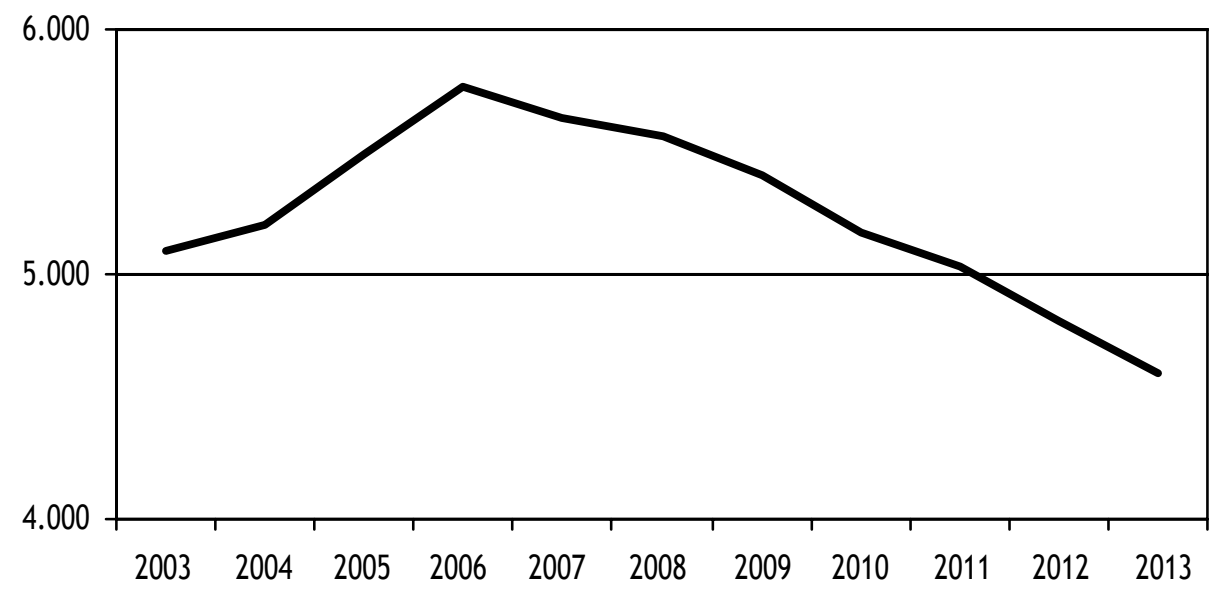

Fuente: Revista Alimarket, 283, 2014, 206-221.

El año 2013 se confirma al acabar este artículo como el peor de la crisis. Los precios medios han caído con lo que los márgenes son cada vez más reducidos y complica la recuperación de la cuenta de resultados. La subida del precio del petróleo, debido a los conflictos y a la especulación de las materias primas, ha dañado todavía más la competitividad de un sector muy sensible a dicho parámetro, dado que el precio del PET y el gasto en transporte son dos partidas relevantes en su estructura de costes. Tras el fuerte crecimiento e inversión de años anteriores, nos encontramos con una enorme capacidad de producción y una notable brecha entre los grandes y los pequeños y medianos productores. Los últimos disponen de una menor capacidad de reacción financiera, aunque muchos sobreviven gracias a la proximidad de sus manantiales al lugar de compra. En España, el componente regional sigue siendo decisivo a la hora de realizar una compra dado que gran parte de la población quiere seguir bebiendo "el agua de toda la vida" que procede del manantial de su provincia o su comunidad. Los localismos no han perdido protagonismo. Algunos también han podido desviar parte de su volumen de producción al canal horeca (Hostelería-Restaurantes-Cafeterías) -aunque la crisis ha afectado de lleno a este canal-y con frecuencia cuentan con el respaldo de las políticas de promoción autonómicas. Pero el descenso de las ventas ante la contracción del consumo constituye un fenómeno general. Las grandes multinacionales no han salido indemnes del proceso afectadas por la pérdida de poder adquisitivo de la población española. Asimismo, muchas pequeñas empresas tuvieron que parar la producción durante el invierno para salvar su cuenta de resultados. A diferencia de otras industrias de bienes de consumo, la salida al exterior no se contempla como una posible solución porque las exportaciones se ven restringidas por el alto coste de transporte que supondría traspasar las fronteras nacionales ${ }^{79}$. Ante la tesitura, los analistas del sector centran sus esperanzas en la recuperación del consumo nacional. Vanas o no, esas esperanzas se confirmarán con los próximos datos de la contabilidad nacional.

79 Ibídem, 228, 2009, 180-200; 239, 2010, 165-195; 250, 2011, 203-225; 254, 2011, 19-74; 283, 2014, 206-221.

\section{Conclusiones}

Al igual que en otros países europeos, la moderna industria del agua embotellada en España nació en la mayoría de los casos ligada a la actividad balnearia que explotaba las fuentes de aguas minero-medicinales dispersas por el territorio peninsular. En una primera etapa los balnearios vendían sus aguas en bebida con fines terapéuticos. El aumento de la demanda, los avances tecnológicos en los procesos de embotellado y la posibilidad de prolongar los tratamientos más allá de la estancia balnearia impulsaron la construcción de pequeños talleres artesanales adyacentes a las estaciones termales. Su producción resultaba bastante modesta y se mantuvo restringida a limitados círculos hasta la Restauración borbónica. Más tarde, en plena Belle Époque empezaron a construirse o renovarse algunas estaciones termales que imitaban el modelo europeo de centros de ocio y sociabilidad y que de manera complementaria embotellaban también sus aguas. En este sentido, durante el primer tercio del siglo XX, el sector de aguas español aumentó su importancia dentro de un negocio termal -al que seguía vinculado en la mayoría de los casos- azotado por la caída en su clientela. Sin embargo, pocos talleres alcanzaban las cifras de las grandes envasadoras europeas, aunque algunos consiguieron colocar sus productos en los mercados exteriores, sobre todo latinoamericanos. Durante esta etapa, nos encontramos una estructura empresarial atomizada compuesta de pequeñas empresas privadas, donde no había penetrado el capital extranjero.

Después de la Guerra Civil, los balnearios languidecieron hasta el cierre de sus instalaciones. La escasez, carestía y autarquía no benefició la recuperación del sector que se demoró hasta la etapa desarrollista. De este modo, mientras la dimensión empresarial de las envasadoras europeas crecía, tanto de manera extensiva como intensiva, y se disparaban los procesos de concentración, la industria de aguas española permanecía clamorosamente atomizada y tecnológicamente atrasada salvo contadas excepciones. El Plan de Estabilización ofreció una clara oportunidad de modernización de la industria que esta aprovechó en un contexto de creciente demanda y apertura exterior. La mayoría 
La explotación empresarial de las aguas mineromedicinales:

la industria del agua embotellada en España (1875-2013)

de plantas envasadoras cortaron lazos con sus casas matrices -los establecimientos balnearios - y las virtudes terapéuticas del agua pasaron a un segundo plano mientras crecía su función de agua de mesa. En paralelo, se produjo un crecimiento del tamaño de las empresas, a la vez que procesos de concentración. En la década de los setenta, las grandes multinacionales del sector comenzaron a penetrar en el mercado español. Las marcas francesas y suizas fueron las primeras en percatarse de las posibilidades que ofrecía España. La conquista fue rápida. La industria todavía no estaba madura, pese a las inversiones realizadas, y antes de abordar la internacionalización vio fagocitadas algunas de sus marcas históricas por el capital foráneo. Más tarde, aterrizarían otras corporaciones internacionales del agua y los grupos de bebidas tanto nacionales como extranjeros. El grado de concentración se ha incrementado en la industria, pero aún se percibe su naturaleza atomizada, dado que junto a una docena de grandes empresas nos encontramos con un universo de PYMEs que luchan por sobrevivir en la crisis actual.

\section{Bibliografía}

Alonso, L., Lindoso, E. y Vilar, M. 2011: 0 lecer das augas. Historia dos balnearios de Galicia, 1700-1936. Vigo, Galaxia.

Alonso, L., Vilar, M. y Lindoso, E. 2012: El agua bienhechora. El turismo termal en España, 1700-1936. Granada, Ministerio de Agricultura, Alimentación y Medio Ambiente-Observatorio del Termalismo.

ANEABE (Asociación Nacional de Empresas de Aguas de Bebida Envasada), 2009: Libro Blanco. Las aguas de bebida envasadas. Madrid, ANEABE.

Anónimo, 2006: "Vichy Catalán vende el 43\% del agua carbónica de España" en Fomento de la Producción, 1262.

Baeza, J., López, J. A. y Ramírez, A. eds. 2001: Las Aguas Minerales en España. Visión histórica, contexto hidrogeológico y perspectiva de utilización. Madrid, Instituto Geológico y Minero de España.

Benavente, J., Castillo, A. y Cruz Sanjulián, J. 1999: Aguas de Sierra Nevada. Aguas de Lanjarón. Los paisajes del agua. Granada, Balneario de Lanjarón, S. A.

Benavente Herrera, J. y Castillo, A. 1999: “Aguas de Lanjarón”, en Durán, J. J. y Nuche, R. (edits.): Patrimonio Geológico de Andalucía. Asturias, ENRESA, 146-149.

Catalán, J. 2003: "La ruptura de posguerra y la industrialización, 19391975" en Nadal, J. (dir.): Atlas de la industrialización de España, 1750-2000. Barcelona, Crítica-FBBVA, 233-338.

Delattre, J. M. 1999: "Las aguas envasadas" en Tampo, D. et al.: Aguas envasadas. Mexico, Limusa Noriega Editores, 19-67.

EUROSTAT, Statistics 1995-2010: Industry, Mineral waters and aerated waters, unsweetened.

Gleick, P. H. 2010: Bottled and Sold: The Story Behind Our Obsession with Bottled Water. Washington, D. C., Island Press.

Green, M. y Green, T. 1986: The Best Bottled Waters in the World. New York, Simon \& Schuster.

INE: Encuesta Industrial de Empresas.

INE: Estadísticas alimentarias de España, 2003-2006. Madrid, INE.
Lamoreaux, P. E. y Tanner, J. T. (eds.) 2001: Springs and Bottled Waters of the World. Ancient History, Source, Occurrence, Quality and Use. Berlin, Springer.

Larrinaga, C. 2011: "Termalismo y turismo en la España del siglo XIX" en Barciela, C. et al. (eds.): La evolución de la industria turística en España e Italia. Palma de Mallorca, Institut Balear d'Economia, 569-608.

Larrinaga, C. y Vallejo, R. 2013: "El turismo en el desarrollo español contemporáneo", en TST: Transportes, Servicios y Telecomunicaciones, 24, 12-29.

LECHE PASCUAL, 2010: Memoria de Responsabilidad Social (http://www. lechepascual.es/docs/rsc/2010/01.Perfil.pdf).

Lindoso, E., Vilar, M. 2014: Orígenes e historia empresarial de la industria del agua embotellada en Europa: el caso español. Documento de Trabajo de la Asociación Española de Historia Económica 1413.

López de Azcona, J. M. 1963: Las aguas minero-medicinales. Su industrialización. Madrid, Instituto de España. Real Academia de Farmacia, 1963.

Marty, N. 2005: Perrier, c'est Nous! Histoire de la Source Perrier et de son personnel. Paris, Editions de l'Atelier.

Marty, N. 2006: "La consommation des eaux embouteillées. Entre alimentation, distinction et hygiène" en Vingtième Siècle. Revue d'histoire, 3, 91, 25-41.

Marty, N. 2008: “''eau embouteillée: histoire de la construction d'un marché" en Entreprises et Histoire, 50, 86-99.

Marty, N. 2011: “Les entreprises d'eaux embouteillées. Éléments pour une comparaison entre la France et l'Espagne (XIXe siècle-début XXe siécle)" en Le Bot, F. y Perrin, C. (dirs.): Les chemins de l'industrialisation en Espagne et en France. Les PME et le développement des territoires (XVIII -XXle siècles). Bruselas, P. I. E. Peter Lang, 227-244.

Memoria facultativa reglamentaria del Establecimiento hidromineral de Verín, Sousas y Caldeliñas, provincia de Orense, temporada de 1891.

Memoria Mondariz, 1879.

Memorias de Sousas, Orense, 1890.

Nobajas i Ganau, A. 2012: "Bottled natural mineral water in Catalonia: Origin and geographical evolution of its consumption and production", tesis doctoral, Universidad de Barcelona, Barcelona.

Pereira, X. M. 2009: El balneario del Lérez. La aventura termal de Casimiro Gómez. Pontevedra, Diputación de Pontevedra.

Piernas, N. 2009: Vichy Catalán. 125 años de historia. Barcelona, Viena ediciones.

Piernas, N., Pous, R. y de Planell, M. 1997: Font de salut: Història del Vichy Catalán. Barcelona, Edicions 62.

Piñar, J. 2006: "El agua como recurso turístico en un entorno rural: el Balneario de Lanjarón" en Balnea, 1, 147-178.

SABI, Sistema de Análisis de Balances Ibéricos.

Sánchez Ferré, J. 2001: "Arquitectura y sociedad. Crónica de los balnearios de España" en Baeza, J., López, J. A. y Ramírez, A. (eds.): Las Aguas Minerales en España. Visión histórica, contexto hidrogeológico y perspectiva de utilización. Madrid, Instituto Geológico y Minero de España, 75-87.

V. AA. 1997: Las aguas de Lanjarón. Granada, Fundación Caja de Granada. 


\begin{tabular}{|c|c|c|c|c|c|c|c|c|c|c|c|c|c|c|c|c|c|c|c|c|c|c|c|c|c|c|c|c|}
\hline & 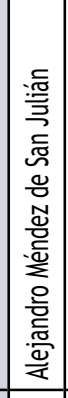 & 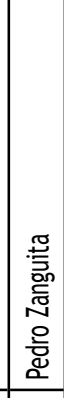 & 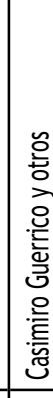 & 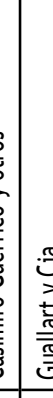 & 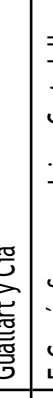 & 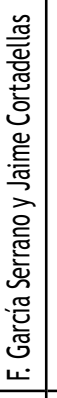 & 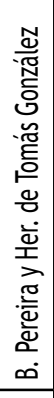 & 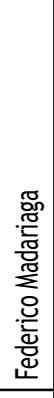 & 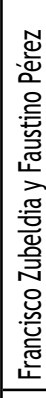 & 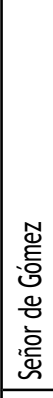 & 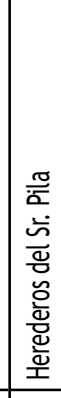 & 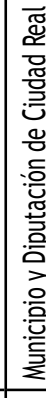 & 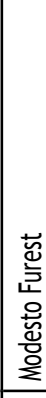 & 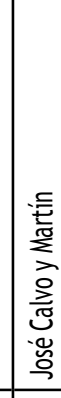 & 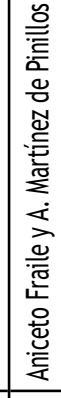 & 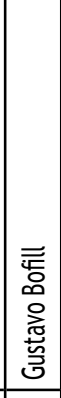 & 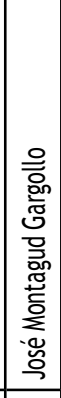 & 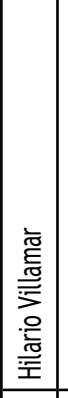 & 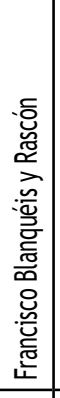 & 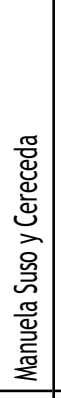 & 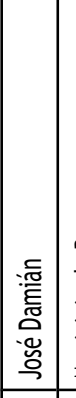 & 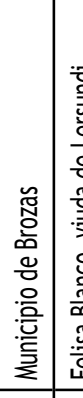 & 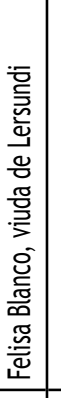 & 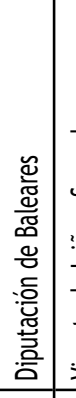 & 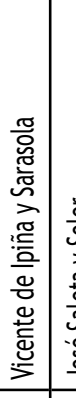 & 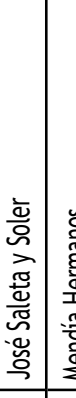 & & 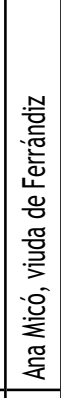 \\
\hline 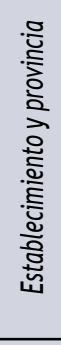 & 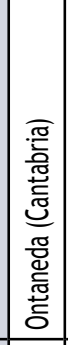 & 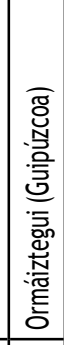 & 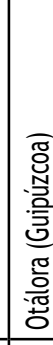 & 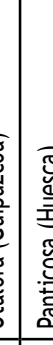 & 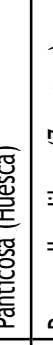 & 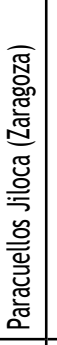 & 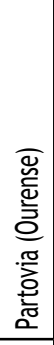 & 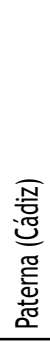 & 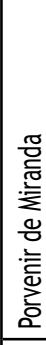 & 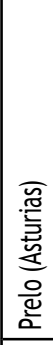 & 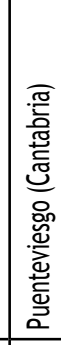 & 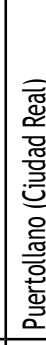 & 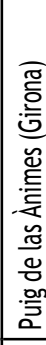 & 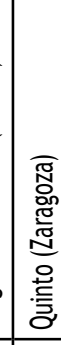 & 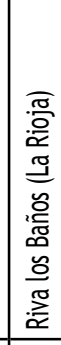 & 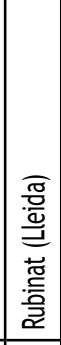 & 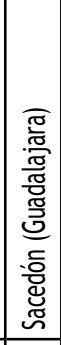 & 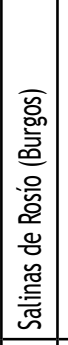 & 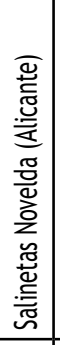 & 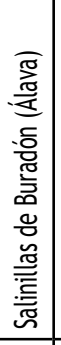 & . & 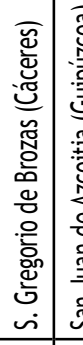 & 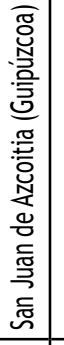 & 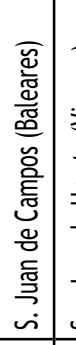 & 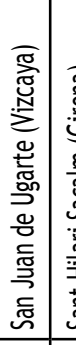 & 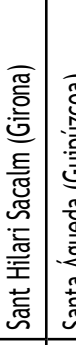 & & 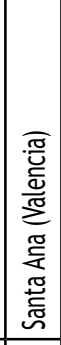 \\
\hline 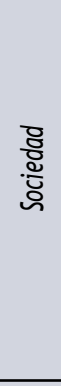 & 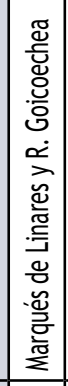 & 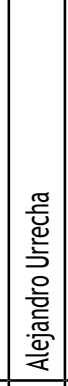 & 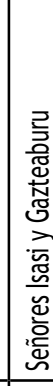 & 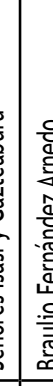 & 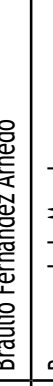 & 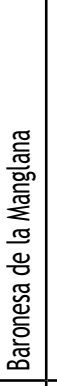 & 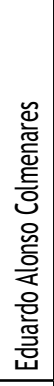 & 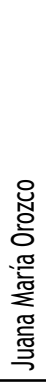 & 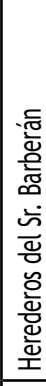 & 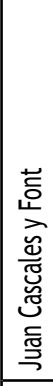 & 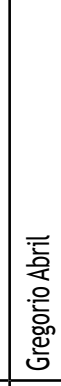 & 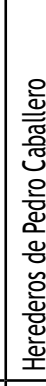 & 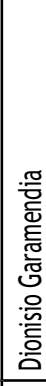 & 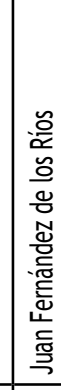 & 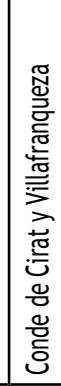 & 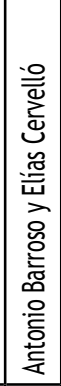 & 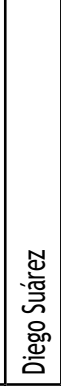 & 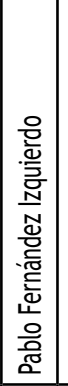 & 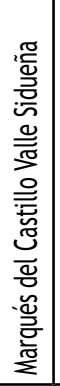 & 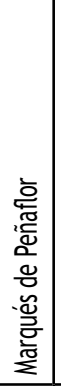 & 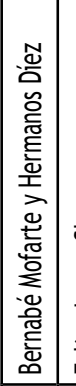 & 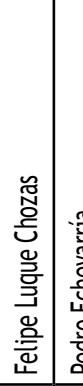 & 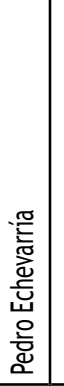 & 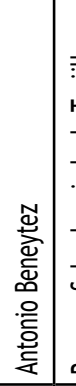 & 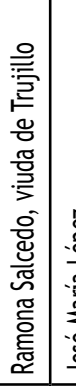 & 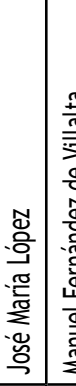 & & 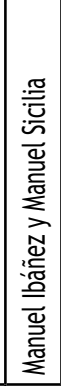 \\
\hline 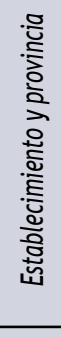 & 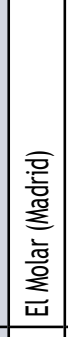 & 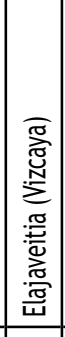 & 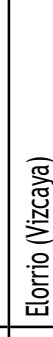 & 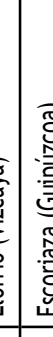 & 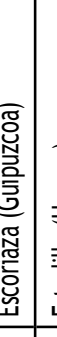 & 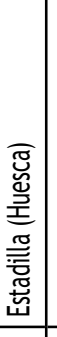 & 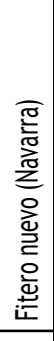 & 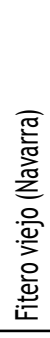 & 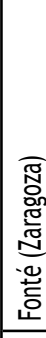 & 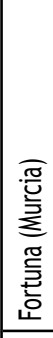 & 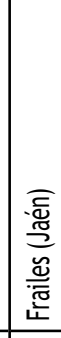 & 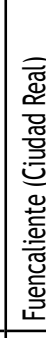 & 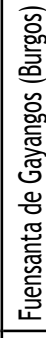 & 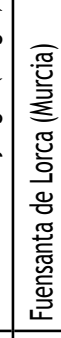 & 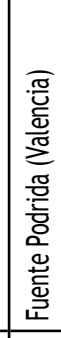 & 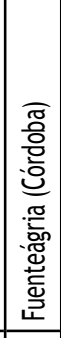 & 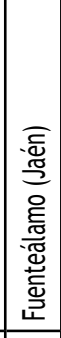 & 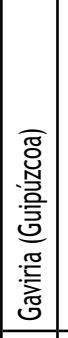 & 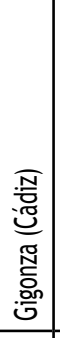 & 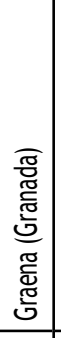 & 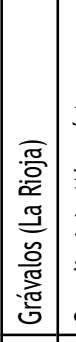 & 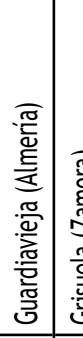 & 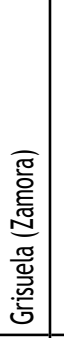 & 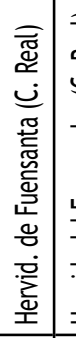 & 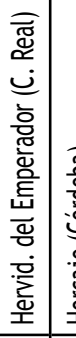 & 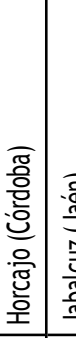 & 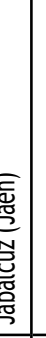 & 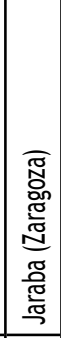 \\
\hline$\frac{8}{8}$ & 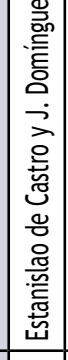 & 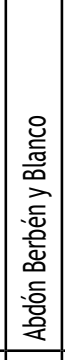 & 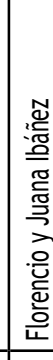 & 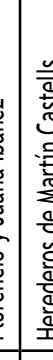 & 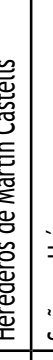 & 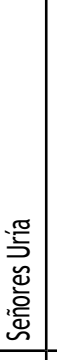 & 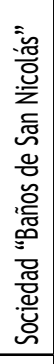 & $\begin{array}{l}\text { 薎 } \\
\end{array}$ & 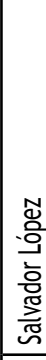 & 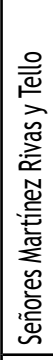 & 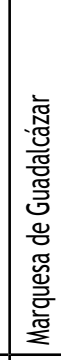 & 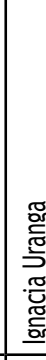 & 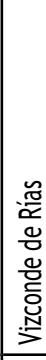 & 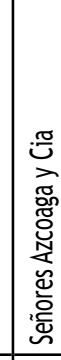 & 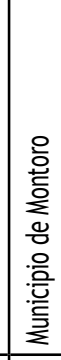 & 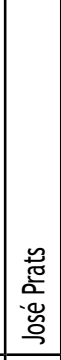 & 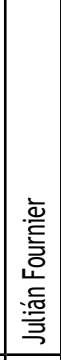 & 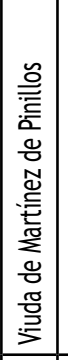 & 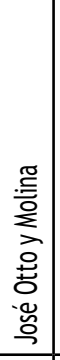 & 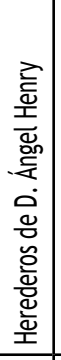 & 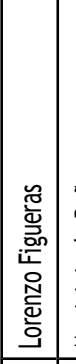 & 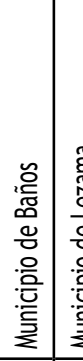 & 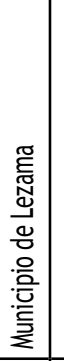 & 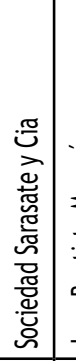 & 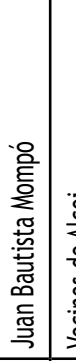 & 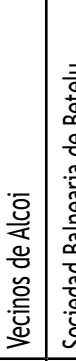 & & 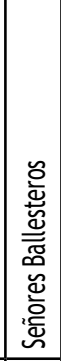 \\
\hline 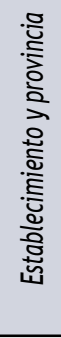 & 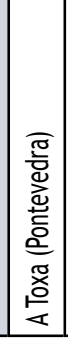 & 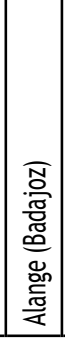 & & $\begin{array}{l}3 \\
z \\
z \\
z \\
z\end{array}$ & & 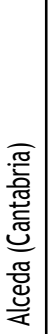 & 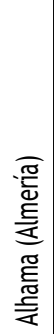 & 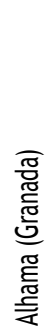 & 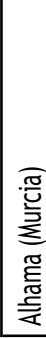 & 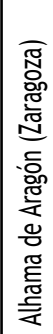 & 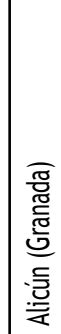 & 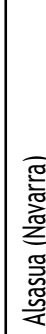 & 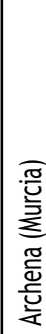 & 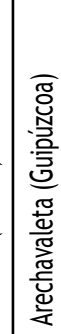 & 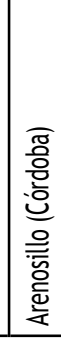 & 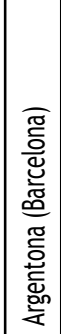 & 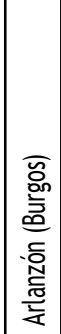 & 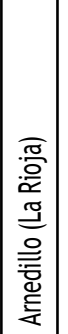 & 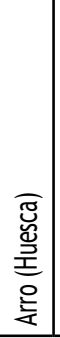 & 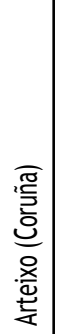 & 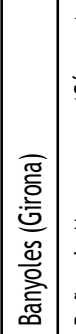 & 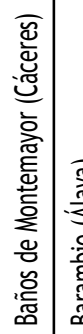 & 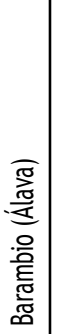 & 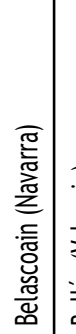 & 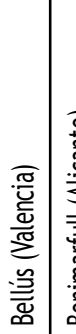 & 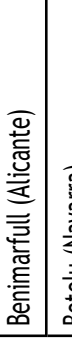 & 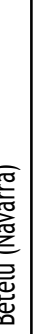 & 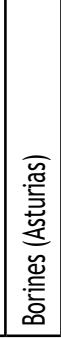 \\
\hline
\end{tabular}


La explotación empresarial de las aguas mineromedicinales:

la industria del agua embotellada en España (1875-2013)

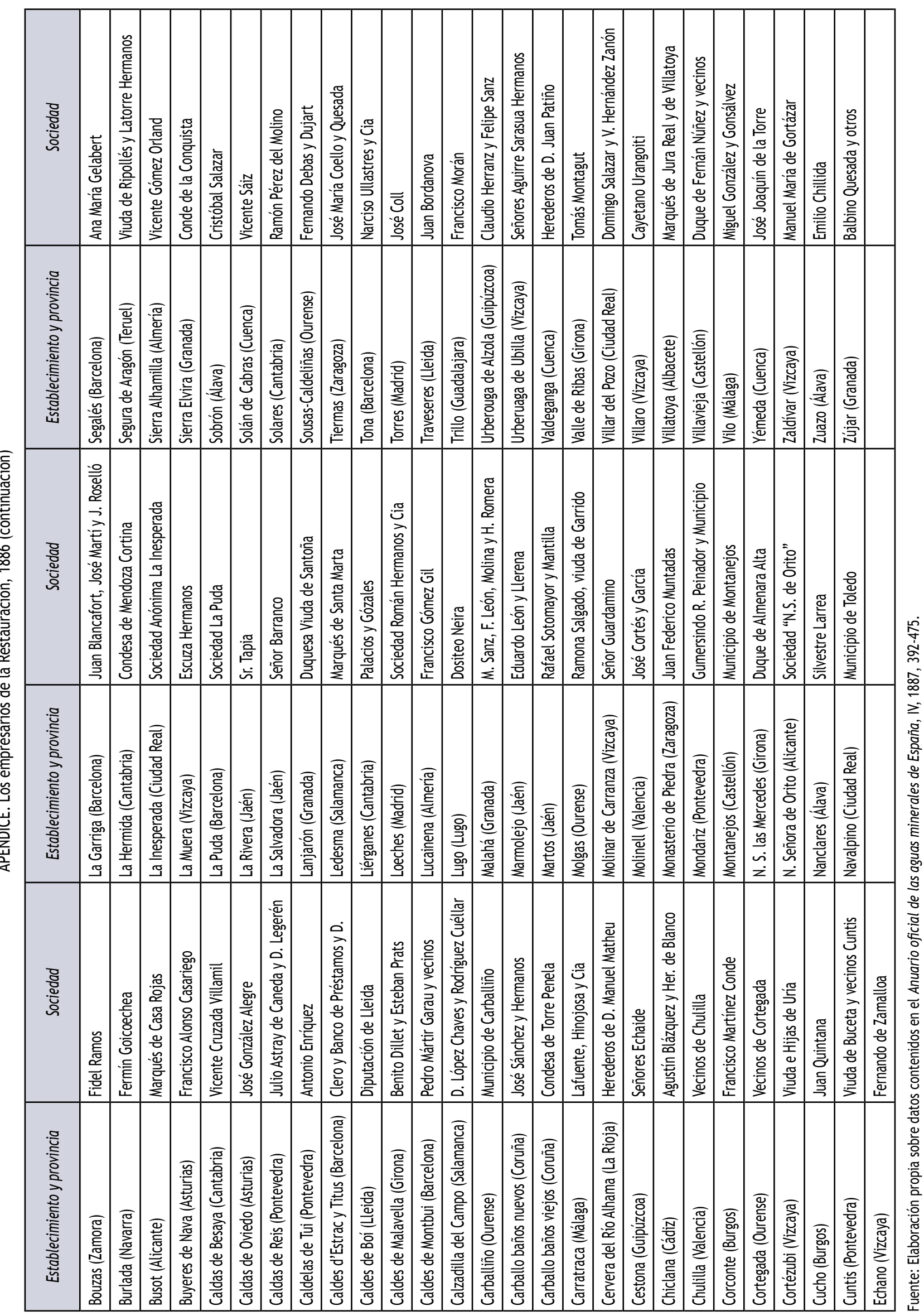

